\title{
Experimental Investigation of a Super Performance Dew Point Air Cooler
}

\author{
Peng $\mathrm{Xu}^{\mathrm{a}, \mathrm{b}}$, Xiaoli Ma ${ }^{\mathrm{b}, *}$, Xudong Zhao ${ }^{\mathrm{b}, *}$ Kevin Fancey $^{\mathrm{b}}$ \\ ${ }^{a}$ Beijing Key Lab of Heating, Gas Supply, Ventilating and Air Conditioning Engineering, \\ Beijing University of Civil Engineering and Architecture, Beijing, China, 100044 \\ ${ }^{\mathrm{b}}$ School of Engineering, University of Hull, UK, HU6 7RX \\ * Corresponding author (Xiaoli Ma): x.ma@hull.ac.uk \\ Tel: +44 (0)1482 466848; Fax: +44 (0)1482 466664 \\ * Corresponding author (Xudong Zhao): xudong.zhao@ @ull.ac.uk \\ Tel: +44 (0)1482 466684; Fax: +44 (0)1482 466664
}

\begin{abstract}
This paper presents an experimental investigation of a super performance dew point air cooler which, by employing a super performance wet material layer, innovative heat and mass exchanger and intermittent water supply scheme, has achieved a significantly higher energy efficiency (i.e. Coefficient of Performance, COP) and a much lower electrical energy use compared to the existing air coolers of the same type. This involves the dedicated system design \& construction, fully planned experimental testing under various simulated climatic conditions representing the climate of hot \& dry, warm \& dry, moderate, warm \& wet and standard lab testing condition, testing results analysis and discussion, as well as the parallel comparison against the commercial dew point air cooler. Under the standard test condition, i.e. dry bulb temperature of $37.8^{\circ} \mathrm{C}$ and coincident wet bulb temperature of $21.1^{\circ} \mathrm{C}$, the prototype cooler achieved the wet-bulb cooling effectiveness of $114 \%$ and dew-point cooling effectiveness of $75 \%$, yielding a significantly high COP value of 52.5 at the optimal working air ratio of 0.364 . The testing also indicated that the lower inlet air relative humidity led to a higher cooling efficiency, while the lower cooling output helped increase COP and cooling effectiveness (including the wet-bulb effectiveness and dew-point effectiveness) of the cooler.
\end{abstract}

\section{Key words}

Dew point cooling; Heat and mass transfer; Dew-point effectiveness; Wet-bulb effectiveness; Coefficient of performance; Experimental investigation 


\section{Nomenclature}

$\mathrm{Q}_{\text {cooling }}$ - Cooling capacity, kW;

$\mathrm{C}_{\mathrm{P}}$ - Specific heat capacity, $\mathrm{kJ} / \mathrm{kg} \cdot{ }^{\circ} \mathrm{C}$;

$\mathrm{T}$ - Air temperature, ${ }^{\circ} \mathrm{C}$;

$\mathrm{T}_{\text {drop }}$ - Temperature drop, ${ }^{\circ} \mathrm{C}$;

$\mathrm{Q}_{\mathrm{m}}$ - Mass flow rate, $\mathrm{kg} / \mathrm{s}$;

COP - Coefficient of Performance;

$\mathrm{W}$ - Electric power consumption, $\mathrm{kW}$;

\section{Greek}

$\Phi$ - working air fraction over the intake air;

$\varepsilon$ - effectiveness;

\section{Subscripts}

dry,in - inlet of dry channel;

dry,out - outlet of dry channel;

wb - wet bulb;

dp - dew point;

fan - fan;

pump - pump;

\section{Introduction}


Rapid growth of the world energy consumption in buildings has raised serious concerns over the depletion of energy resources and global climate change [1]. In the developed countries, energy consumption in heating, ventilation and air-conditioning (HVAC) systems has taken up around $50 \%$ of the total building energy use, which represents around $20 \%$ of the total energy use in these countries. In some developing countries, e.g. China, energy use by HVAC systems accounted for $50 \%$ to $70 \%$ of the energy supplied to buildings [2, 3].

Cooling is an important function of a HVAC system and energy consumption for cooling is significant, ranging from $10 \%$ to $90 \%$ of the total HVAC system, dependent upon the geographical location, occupancy density, building type and function etc $[4,5]$. In hot climatic regions, e.g. Middle-East, South-East Asia etc, air conditioning represents the full function of HVAC systems. To tackle the energy intense difficulty of existing building air conditioning systems, developing energy efficient and sustainable cooling technologies appropriate to building application is of great importance.

Air conditioning market is currently dominated by mechanical vapour compression refrigeration systems. This type of system consumes significant amount of electricity owing to the use of the compressor, and therefore, is neither sustainable nor environmentally friendly [6]. Absorption or adsorption cooling, as a potential alternative to conventional mechanical vapour compression systems, removes the need for the power-intensive compressor, but adds up the requirement for high temperature vapour or water, thus limiting its application to the sites where high temperature heat source is not available. Further, relatively complex system configurations containing pressurised and de-pressurised components in the absorption and adsorption systems reduces their attraction to the users [7].

Over the past decades, evaporative cooling, by making use of the principle of water evaporation for heat absorbing, has gained the growing popularity for the use in air conditioning [8,9], owing to its simple structure and good use of the latent heat of water, which is a recyclable (renewable) energy existing in natural environment. Evaporative cooling systems include two general types: direct and indirect ones. Direct Evaporative Cooling (DEC) keeps the primary (product) air in direct contact with water, causing evaporation of the water and reduction of air temperature simultaneously. As a result, the 
vaporised water, in a form of vapour, is added into the air, creating a wetter air condition and causing discomfort to occupiers. Indirect Evaporative Cooling (IEC) keeps the primary (product) air at the dry channels and the secondary (working) air at the neighbourhood wet channels where water is distributed towards the surfaces to form the thin water films. The cooling of the product air (PA) is achieved by the heat transfer between the adjacent primary and secondary air streams, with the assistance of water evaporation on the wet channel surfaces. This kind of cooler can lower the temperature of air and meanwhile keep its dryness, thus creating a better thermal comfort and improved indoor air quality [10-12]. Unfortunately, owing to the theoretical constraint of the air's wet bulb temperature, this system has very limited temperature reduction potential [13] which has restricted its wider application in buildings. Dew point cooling, by modifying the structure of heat and mass exchanger (HMX) to enable the pre-cooling of the secondary air prior to its entry into the wet channels, can break up the wet bulb limit and lower the air temperature down to its dew point, thereby achieving 20\%-30\% higher cooling efficiency than conventional IECs [3, 14-17]. Owing to this distinguished advantage, the dew point cooling technology has drawn the growing attention to researchers, industrial personnel, as well as users.

Researches into HMXs for dew point cooling are numerous, and can be broadly classified as the experiment based works $[15,18,19]$, simulation based works and combined experiment and simulation works [20-35]. In terms of experimental work, Bruno [18] constructed a flatplate cross-flow HMX that used a special sheet with high water retention and wicking capability as the wet material layer, and a water-proof membrane as a dry material layer. The tests indicated that the exchanger had an average dew-point effectiveness of $75 \%$, which was relatively higher than that of the existing types for the same operational conditions.

Riangvilaikul et al [19] tested a novel vertically configured dew point air cooler (DPC) which has the counter-current flow patterns between the intake air and working air and between the working air and water. The tests were carried out under various inlet air conditions and the results indicated that the wet-bulb effectiveness of the cooler was in the range $92-114 \%$ and the dew-point effectiveness in the range 58-84\%. Coolerado ${ }^{\circledR}$ (USA) developed a cross-flow HMX with perforated holes on the flow paths. The test indicated that this type of HMX could achieve wet-bulb and dew-point effectiveness of around $80 \%$ and $50 \%$ under a specific operational condition [15], which was around $20 \%$ higher than that of conventional IECs. 
In terms of computer simulation and combined modelling and experiment, Hasan [20] developed an analytical model of a regenerative counter-flow IEC with a modified e-NTU method and validated the results using an established numerical model and experimental data. Lin et al [21] presented a numerical study to a dew point cooling system with counter-flow pattern. It was found that the saturation point of the working air occurred at a fixed point irrespective of inlet air conditions, while the position where the water started to evaporate was 0.2 to $0.3 \mathrm{~m}$ above the entrance and the overall heat transfer coefficient was greater than $100 \mathrm{~W} /\left(\mathrm{m}^{2} \cdot \mathrm{K}\right)$ within the wet channel of the unit. Cui et al $[22,23]$ proposed a numerical model of a counter-flow dew point evaporative cooler based on M-cycle and theoretical investigation indicated that when the room return air was used as the working air and the cooler was installed with ribs instead of a plain channel, the cooling effectiveness could be effectively increased. The dimensions of the channel had a significant impact on the cooling effectiveness. Lin et al [24] proposed a transient model for a counter-flow dew point cooling system, indicating that the dynamic behaviour of the dew point evaporative cooler is crucial in achieving an efficient cooling. It was also found that the proposed transient model could predict the PA temperature with a maximum discrepancy of 4.3\%. Pandelidis et al [25] developed a two-dimensional heat and mass transfer model and investigated eight different HMXs of M-Cycle used in dew point cooling. The simulation results were compared with the testing data to find a solution to improve the performance of the HMX. Pandelidis et al [26] described the optimization process of a cross-flow M-cycle DPC using both the singleparameter and multi-parameters methods. The multi-parameters optimization method, based on the analysis of the Harrington function of desirability, could give satisfactory results, and thus enabled identification of the optimal operational and geometrical conditions for the HMX and determination of the optimum climatic conditions for its effective operation.

Furthermore, Sohani et al [27] presented a numerical model for simulating the performance of DPCs with an M-cycle cross-flow heat exchanger. This model employed a novel data handling neural networking method to carry out the statistical work. The features of the proposed system were optimised for twelve diverse climatic conditions in the world, based on Koppen-Geiger's classification. Moshari and Heidarinejad [28] presented numerical simulation to the cross- and counter-flow Regenerative Evaporative Coolers (REC) and a cross-flow IEC cooler and associated experimental validation. The results showed that the 
counter-flow REC could achieve $30 \%$ higher wet-bulb effectiveness than the cross-flow type of the same size. When increasing the working air ratio from 0.2 to 0.9 , the wet-bulb effectiveness of the cooler increased by $10 \%-20 \%$. Chen et al [29] focused on study of the condensation problem occurring in the dry channels at high dew point temperature of the fresh air. They conducted parameter sensitivity analysis among seven parameters by orthogonal test based on the experimental-validated IEC model emphasizing on condensation condition. The results indicated the channel gap and cooler height were the key factors that impact on the IEC thermal performance.

Kabeel et al [30] numerically and experimentally investigated the performance of a novel indirect evaporative cooler with internal baffles. The effect of the inlet conditions (inlet air temperature and humidity ratio) was studied and the results showed that for five cooler configurations under different inlet air conditions, the outlet air temperature decreased by increasing the number of baffles. Riangvilaikul and Kumar presented a numerical study of a counter-flow HMX [31], involving numerical simulation of the heat and mass transfer process within the flow channels, and associated experimental validation [32]. The reasonable agreement was achieved between the numerical and experimental results, giving $5 \%-10 \%$ deviation in terms of the outlet air temperature and cooling effectiveness, respectively. The wet-bulb effectiveness of the unit was in the range $92 \%-114 \%$, higher than that of the same-sized cross-flow exchanger. Jradi et al. [33] carried out a combined numerical and experimental investigation of a modified dew point cooling system that contains a cross-flow HMX with channel height of $5 \mathrm{~mm}$ and channel length of $500 \mathrm{~mm}$. With the intake air temperature of $30^{\circ} \mathrm{C}$, relative humidity of $50 \%$ and working-to-intake air ratio of 0.33 , the system achieved a wet-bulb effectiveness of $112 \%$ and a dew-point effectiveness of $78 \%$.

Although many advances in dew point air-cooling have been realised, the temperature reduction potential of this type of cooler is still relatively low, resulting in problems of larger size, larger air flow rate and higher cost. The critical challenges lie in (1) limited heat transfer capacity of the HMX; (2) poor water absorption and diffusion capacity of the heat exchanging sheets; and (3) higher electrical power demand by the pump and fans. To tackle 
these problems, this research developed a novel complex HMX that, compared to conventional flat-plate heat exchangers, presented the following distinguished advantages:

- Removal of the use of the channel supporting guides leads to significantly reduced air flow resistance

- Implementation of the corrugated heat transfer surface as a replacement of flat-plate surface leads to increased the heat transfer area [34].

- A super performance wet material layer, i.e., Coolmax ${ }^{\circledR}$ fabric, has been identified. This material, owing to its larger capillary force, high water diffusivity, excellent moisture evaporation rate, as well as strong binding capability with the dry-side material compared to other applicable material [35], could generate higher water absorption, diffusion and evaporation effects over others.

- The high absorption capacity of the wet material layer for significant water retention created an opportunity to implement the intermittent water supply scheme that can minimize the water usage and water pump power consumption.

- As an alternative, the system could also use the in-house tap water directly, thus eliminating the use of a circulating water pump and associated power consumption.

Based on the combination of above innovations, this paper reported the dedicated design, construction and experimental processes of a 4-kW rated super performance dew point air cooler and associated results analysis. The practical effects of the innovations were examined during the performance tests of the cooler and will be reported in the following sections.

\section{Description of the complex HMX and associated prototype DPC}

\subsection{The complex HMX}

A schematic of such a complex HMX is shown in Fig. 1. Compared to the conventional flatplate HMXs, the new exchanger removed the use of channel supporting guides and implemented the corrugated heat transfer surface. This can decrease air flow resistance by around $50-56 \%$, and increase the heat transfer area by around $40 \%$, thus leading to the increase of the same percentage of heat transfer rate [34]. 
This kind of HMX comprises numerous unibody heat exchanging sheets, each of which is the combination of a dry material layer (i.e. a specific aluminium with high malleability) and a wet material layer (i.e. Coolmax ${ }^{\circledR}$ fibre with excellent water absorption/diffusion/evaporation capacity) by using an excellent marine adhesive (i.e. Sikaflex ${ }^{\circledR}$-291i). This provides the sheets with high flexibility in complex shape formation (i.e. flat geometry at the inlet/outlet portions and corrugated geometry at the main heat transfer portion), and creates perfect water absorption, diffusion and evaporation effect on the wet surface [35], thus significantly improving its cooling performance. Further, the Coolmax ${ }^{\circledR}$ fibrous layer has a very thin thickness $(0.1-0.3 \mathrm{~mm})$ that leads to the reduced thermal resistance and increased heat transfer rate. The fibre has the features of high durability, easy of shaping, cleaning and replacement, and thus is particularly suitable for indirect evaporative cooling application.

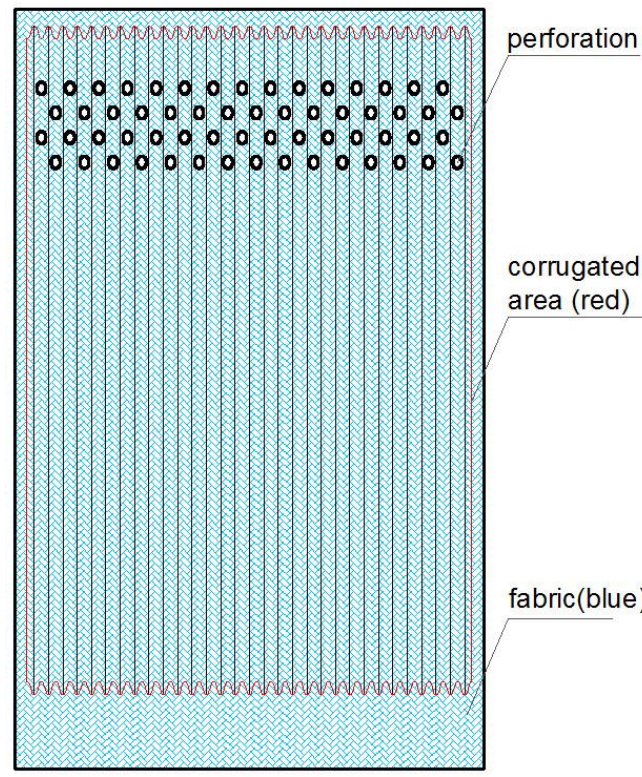

(a) Unibody exchanging sheet

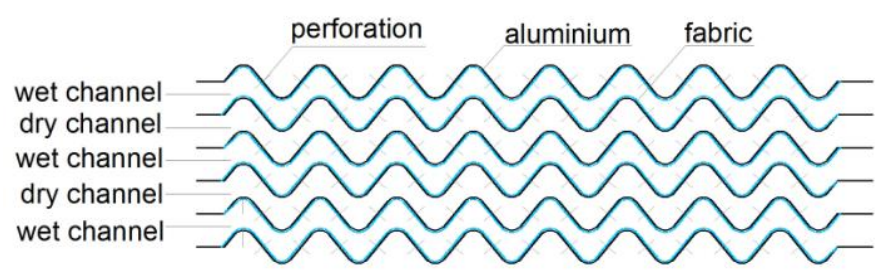

(b) Air channels formed with the exchaning sheets 


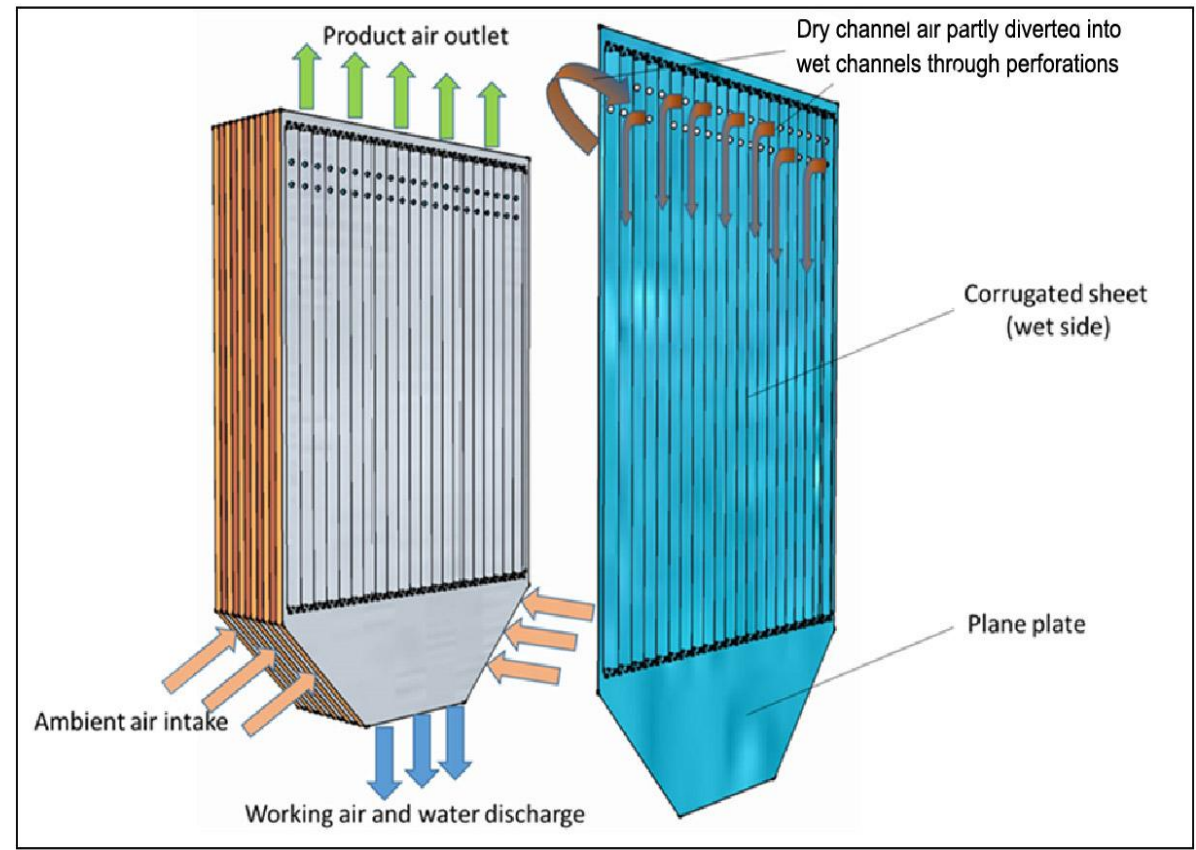

(c) Exchanger stacked with unibody exchanging sheets

Fig. 1: Schematic drawing of the complex HMX.

With these integrated innovations, a 4-kW rated HMX was designed. As shown in Fig. 2, the HMX has the dimensions of $1000 \mathrm{~mm}(\mathrm{H}) \times 358 \mathrm{~mm}(\mathrm{~L}) \times 800 \mathrm{~mm}(\mathrm{~W})$. Along the $1000 \mathrm{~mm}$ length of the flow channel, the lengths of the inlet \& outlet flat planes and corrugated section are $120 \mathrm{~mm}, 10 \mathrm{~mm}$ and $860 \mathrm{~mm}$, leaving two 5-mm-length transitional sections between the flat planes and corrugated section. Based on the dedicated numerical simulation [34] as well as the consideration for ease of manufacture, the height and width of each corrugated wave were determined as $2.8 \mathrm{~mm}$ and $11.6 \mathrm{~mm}$ respectively. On the top side of each heatexchanging sheet, numerous perforated holes were opened to allow part of the dry channel air to be diverted to the neighbourhood wet channels, thus enabling the heat transfer between the two parts of air streams and cooling of the dry channel air. The structural views of the heat exchanging sheets and the whole HMX are shown in Fig. 3. 


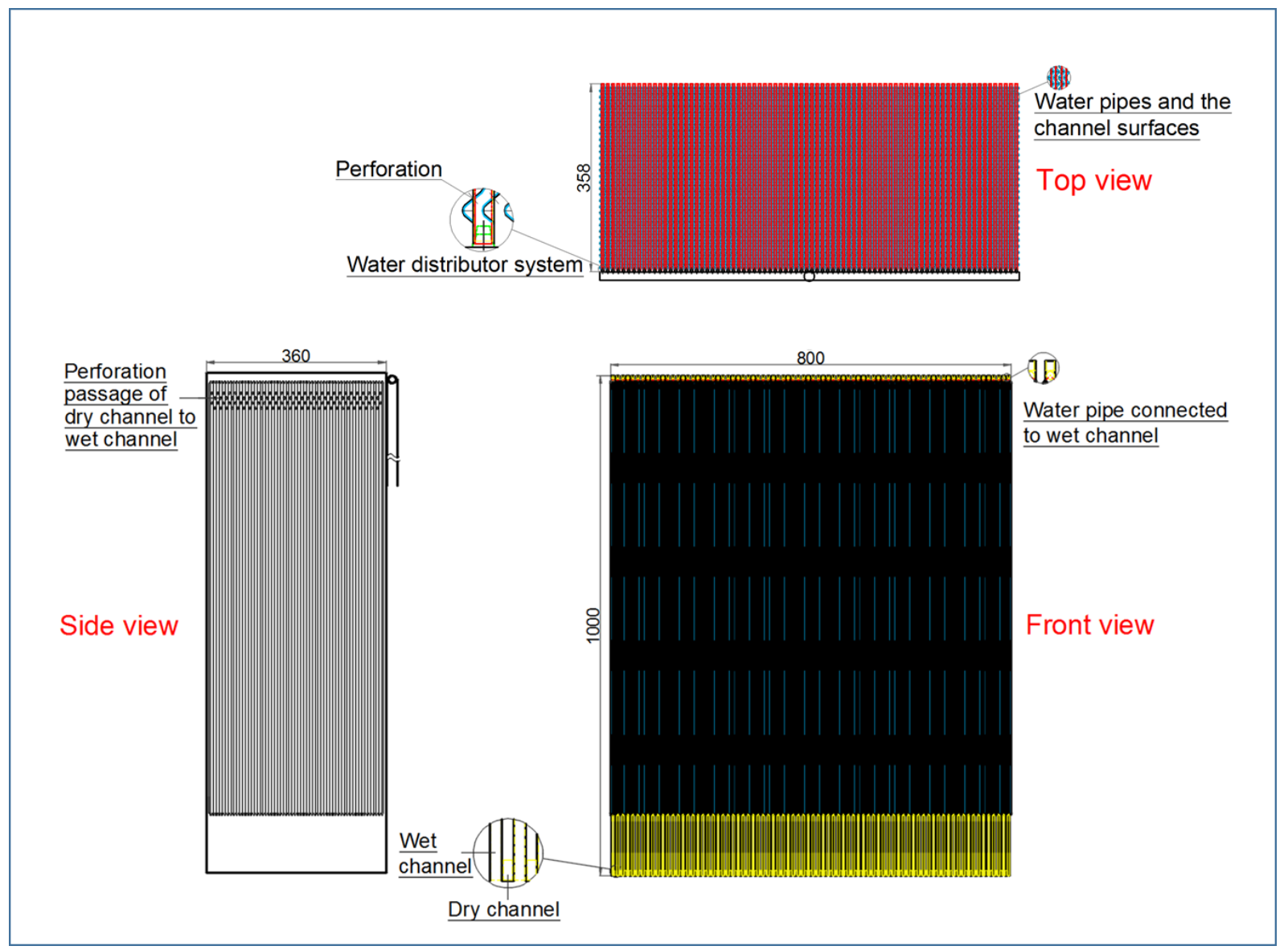

Fig. 2: Design drawings of the HMX.
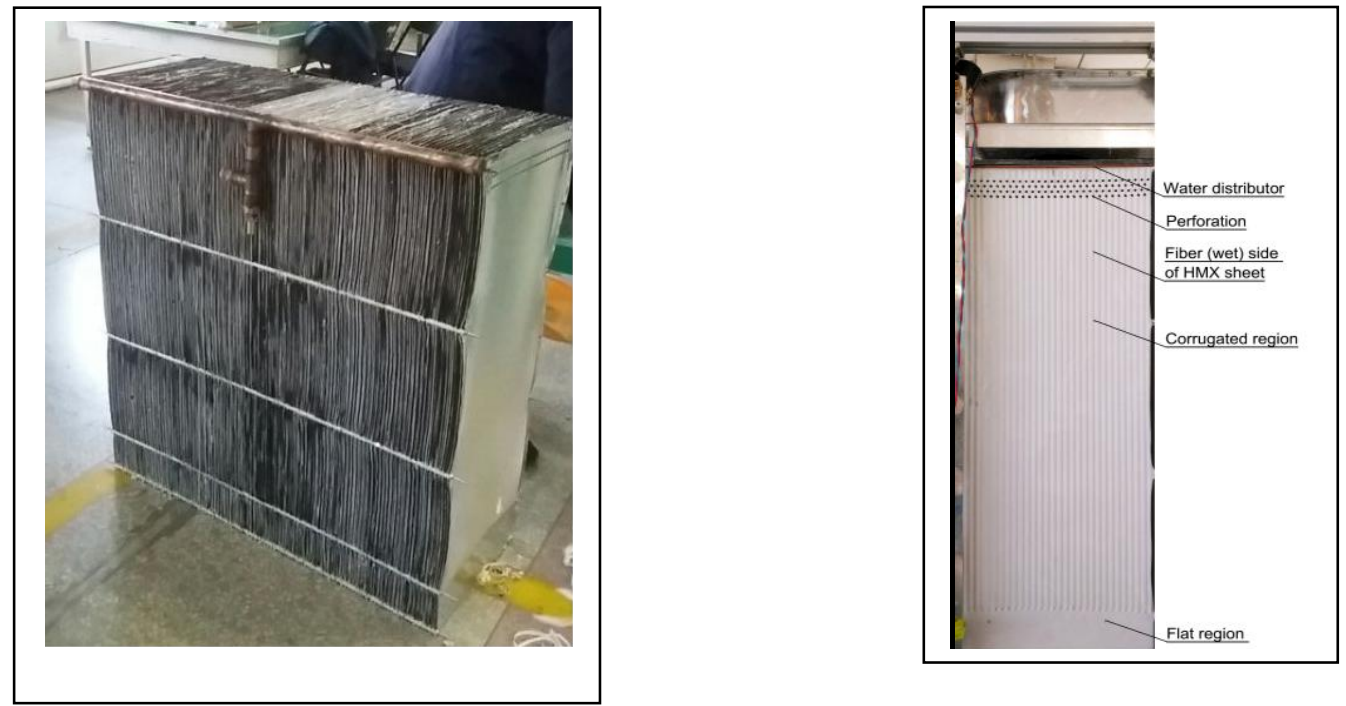

(a) HMX

(b) Heat exchanging sheet in position

Fig. 3: Structural views of the HMX. 


\subsection{Water supply scheme and water distributor}

The high absorption capacity of the fibrous layer enables it to hold significant amount of water for a relatively longer period. This created an opportunity to implement the intermittent water supply scheme that can minimize the water usage and water pump power consumption. To enable achieving the desired water supply and distribution, a dedicated water distributor [36] was constructed. This configuration, as shown in Fig. 4(a), comprises a main water supply pipe, a horizontal water header and numerous small-sized water distribution tubes, all of which were appropriately jointed together to form an integrated unit. During operation, the main water supply pipe, connecting to a circulating pump and/or an in-house water tap (coupled with the main municipal pipe network), received the water for the designed time interval. This amount of water was then delivered to the horizontal water header that can balance the pressure of water and distribute it to each water distribution tube. It should be noted that a single distribution tube was drilled with numerous tiny openings $(0.5 \mathrm{~mm}$ in diameter and diminishing gaps between the two adjacent openings as per change of water flow rate along each branch pipe) and inserted into a wet channel of the HMX (see Fig 4(b)). This allowed the water to be evenly distributed across the surfaces of the wet channel. The structural view of the water distributor is shown in Fig. 4(a) and (b).

Further, the water was delivered intermittently with the scheme below (see Fig. 5): (1) when the bottom water sink was not full, the water supply pipe was connected to an in-house water tap, running 15 seconds for every 10-minute interval with the flow rate of 6.85 litre per minute; (2) when the bottom water sink was full, the water supply pipe was switched to the circulating pump, running 60 seconds for every 10-minute interval with the flow rate of 2.45 litres per minute. To realise this operating scheme, two sensors were installed into the water sink that can measure the lower and upper levels of the water within the tank and instruct the action of the electromagnetic valve fitted into the water supply system of the unit. The sensors and the electromagnetic valves used in the system are shown in Fig. 6.

To prevent the potential block of tiny holes of the water distributors during practical application, three approaches are considered and these are: (1) a water filter with cartridge, 
which can purify and demineralise water effectively, will be applied to the intake water; (2) anti-scale agent will be introduced to help remove the potential blockage; and (3) minimising the use of the intake water and maximise the use of the circulating water within the cooler.

The water temperature and water volume impose an impact to the performance of the cooler. In term of a lower water temperature and a higher water flow rate, a sensible heat transfer from the water to the air will be significant and consequently, the latent heat transfer resulted from the evaporation of the water will be weaken. In term of the continuous water circulation, i.e., the inlet water temperature is basically equal to the outlet water temperature within a wet channel, the water temperature might stay at a relatively higher level and might contribute to the rise of the product-air's temperature. In this case, the water flow rate is the key factor that affects the performance of the cooler. In this experiment, the water volume flow rate was controlled to a very low level and an intermittent water supply scheme was applied. The temperature of water from the main supply was kept at around $16^{\circ} \mathrm{C}$ and the temperature of circulating water from the water sink was controlled to a level of $20^{\circ} \mathrm{C}$. In this case, the impact of water temperature onto the performance of cooler could be very minor and so will not be discussed in this paper.

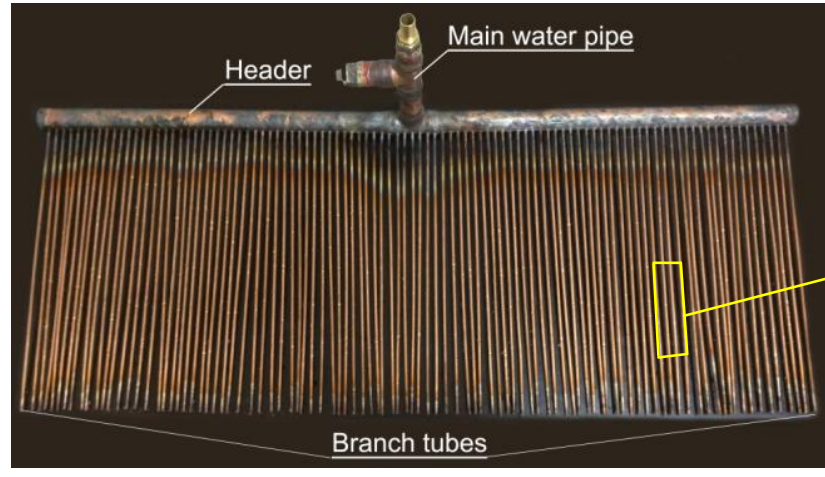

(a) Water distributor

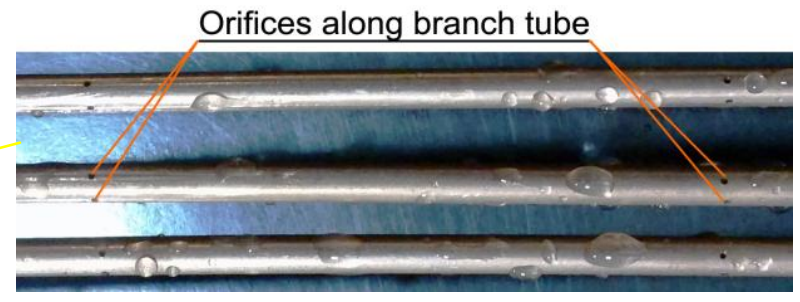

(b) openings setting on the distribution pipes

Fig. 4: Structural view of the water distributing system. 


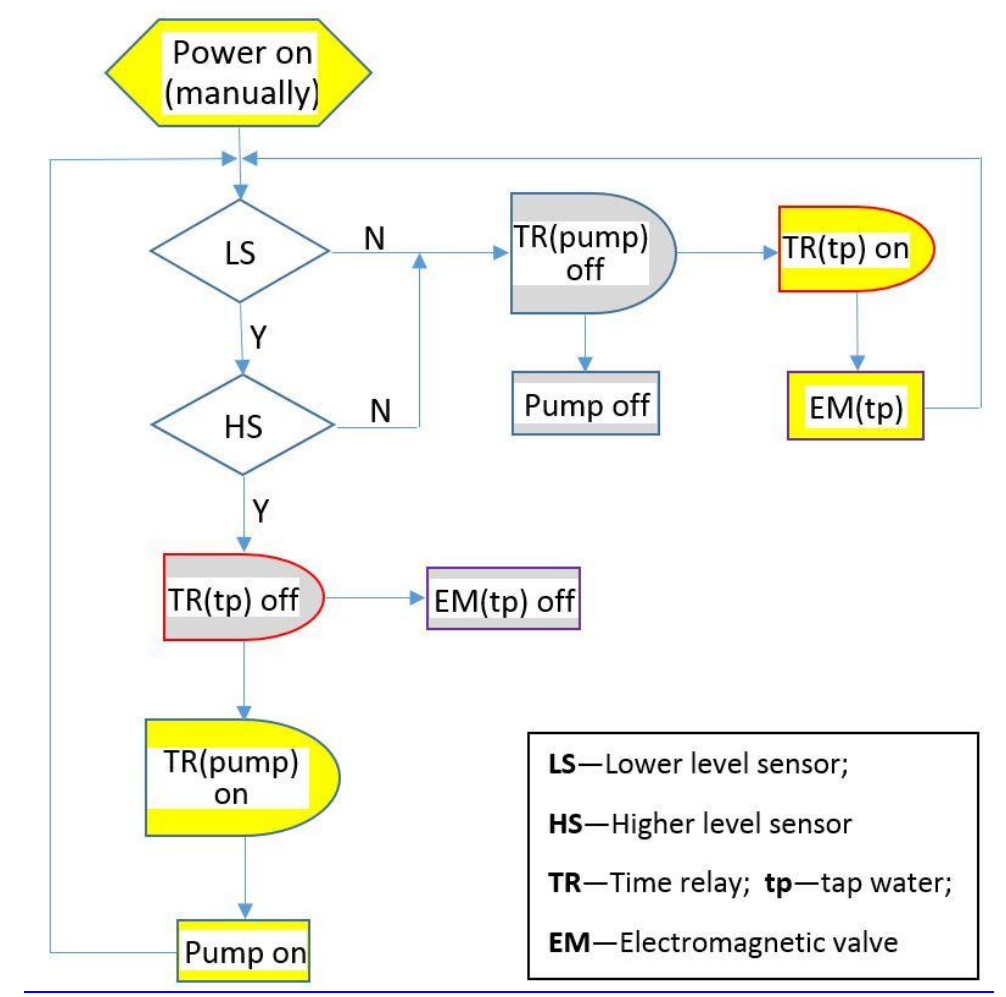

Fig. 5: Control logic of water supply.

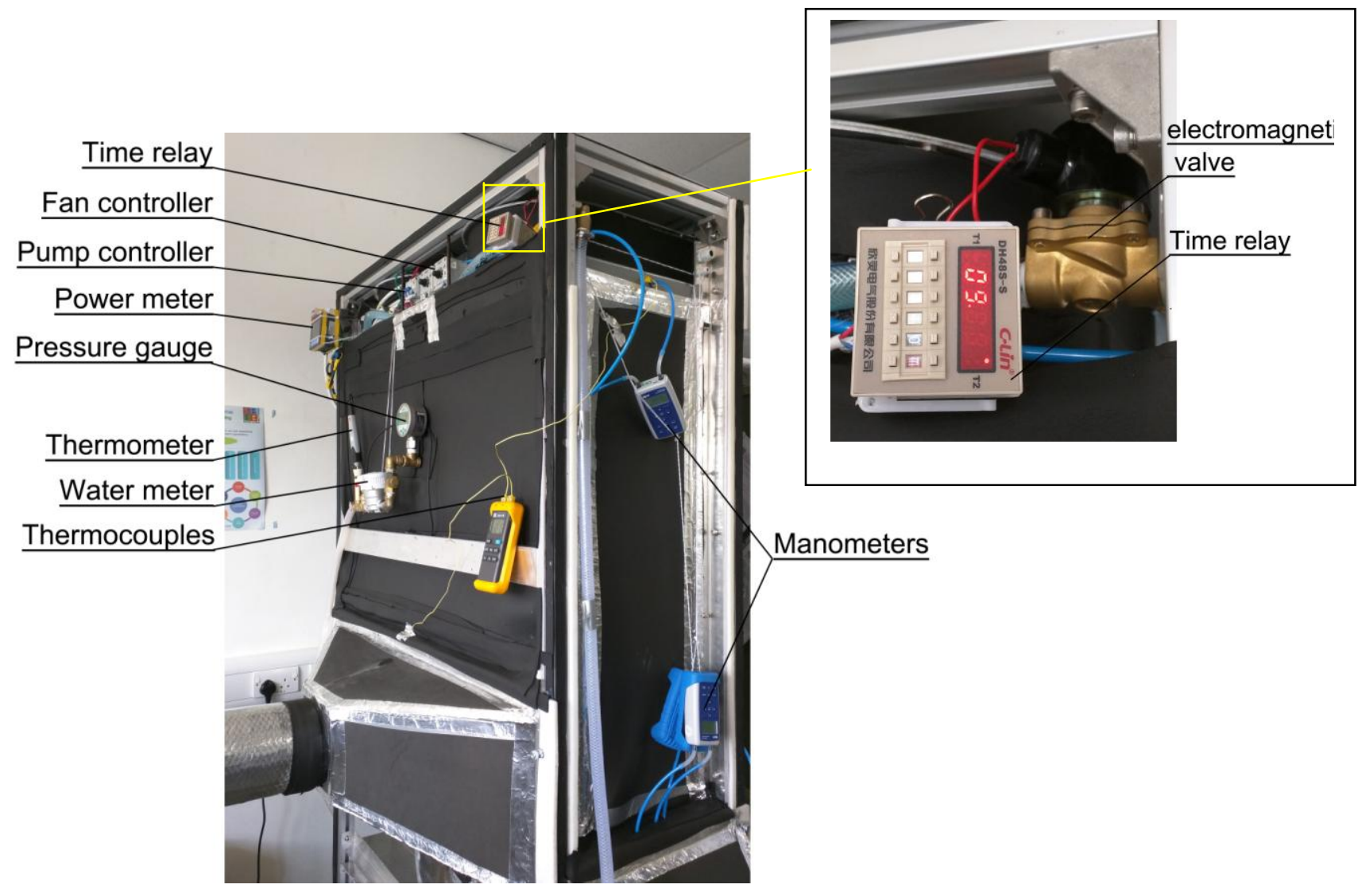

Fig. 6: Layout of the measurement instruments and control elements. 


\subsection{The fans, pump and controllers}

Four energy efficient fans, two for the supply air and the other two for the exhaust air (EA), and one circulating pump, were emploied; these are detailed in Table 1. To enable the timely alteration between the selected operating schemes, the dedicated fan and pump controllers were selected and their technical specifications are presented in Table $\mathbf{1}$.

Table 1. Technical specifications of the fans, pump and associated controllers.

\begin{tabular}{|l|l|c|}
\hline \multicolumn{1}{|c|}{ Component } & \multicolumn{1}{|c|}{ Specification } & Quantity \\
\hline Supply air fan & $\begin{array}{l}\text { R3G225-RE07-03, ebm-papst Ltd, fan speed } \\
2865 / \mathrm{min}, 705 \mathrm{~m}^{3} / \mathrm{hr}, 458 \mathrm{~Pa}, 160 \mathrm{~W}\end{array}$ & 2 \\
\hline Exhaust air fan & $\begin{array}{l}\text { R3G225-RE07-03, ebm-papst Ltd, fan speed } \\
2865 / \mathrm{min}, 705 \mathrm{~m}^{3} / \mathrm{hr}, 458 \mathrm{~Pa}, 160 \mathrm{~W}\end{array}$ & 2 \\
\hline $\begin{array}{l}\text { Circulated } \\
\text { water pump }\end{array}$ & $\begin{array}{l}\text { DH4OH-24110, Shenzhen Zhongke Century } \\
\text { Technology Ltd, 24V/ 1.2A DC, 11mH } \mathrm{H}_{2} \mathrm{O}, 450 \mathrm{~L} / \mathrm{hr}\end{array}$ & 1 \\
\hline Fan controller & 980-CAS11007 - TMS Controller, ebm-papst Ltd & 1 \\
\hline Pump controller & DH48S-S, Xinling Electrical Co. Ltd & 1 \\
\hline
\end{tabular}

\subsection{The integrated system and its operational schedule}

The DPC comprises an integrated HMX, two supply fans, two exhaust fans, one circulating pump, a water tank, a water piping loop, the inlet/supply/exhaust air vents, and controllers for the pump and fans, all of which are fitted into a metal case that formulated an integrated cooling unit. The design drawings and real structure of the integrated unit are shown schematically in Figs. 7 and $\mathbf{8}$ respectively, while the illustration of the air treatment process on the psychometric chart is shown in Fig. 9. 

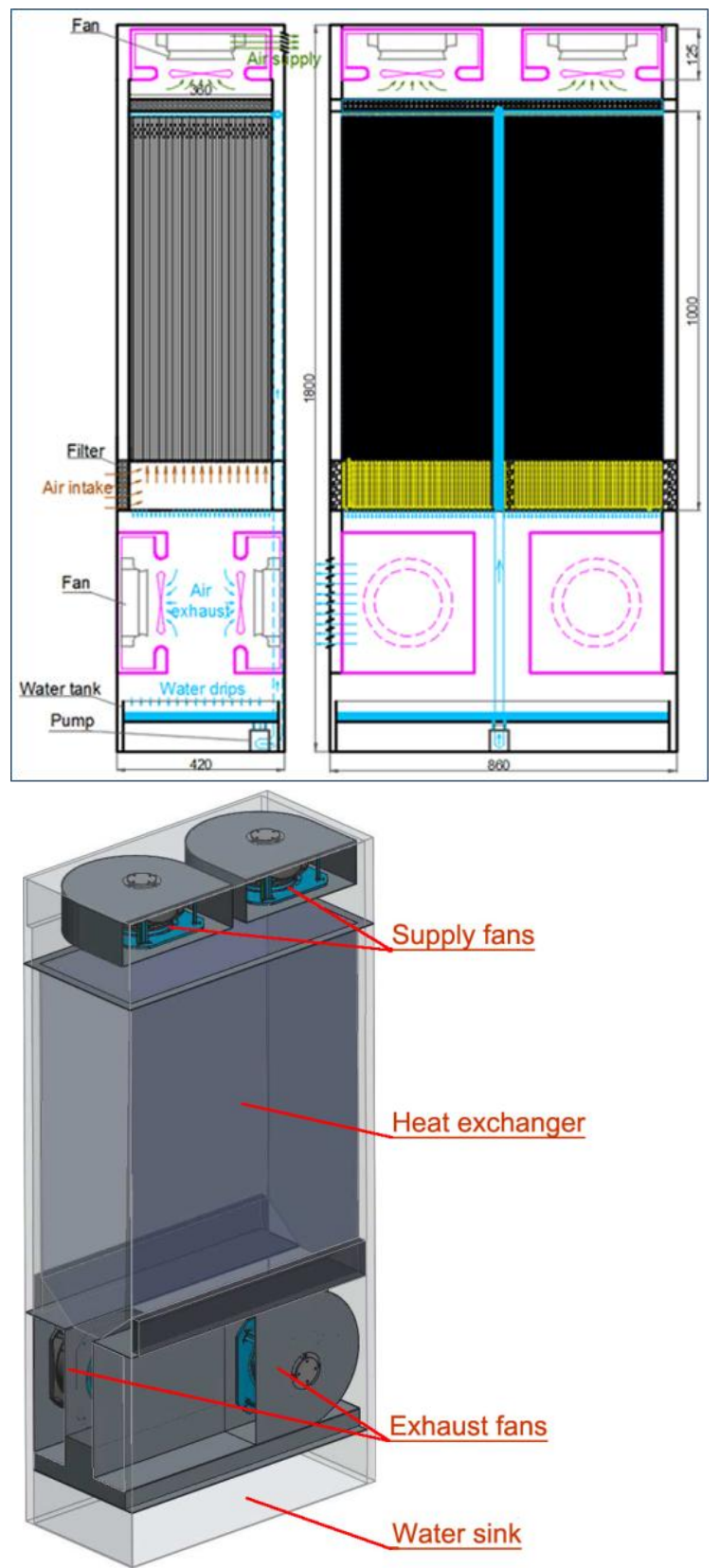

\section{(a) 2-view drawing}

(b) 3-d model

Fig. 7: Design drawings of 4-kW lab prototype system. 


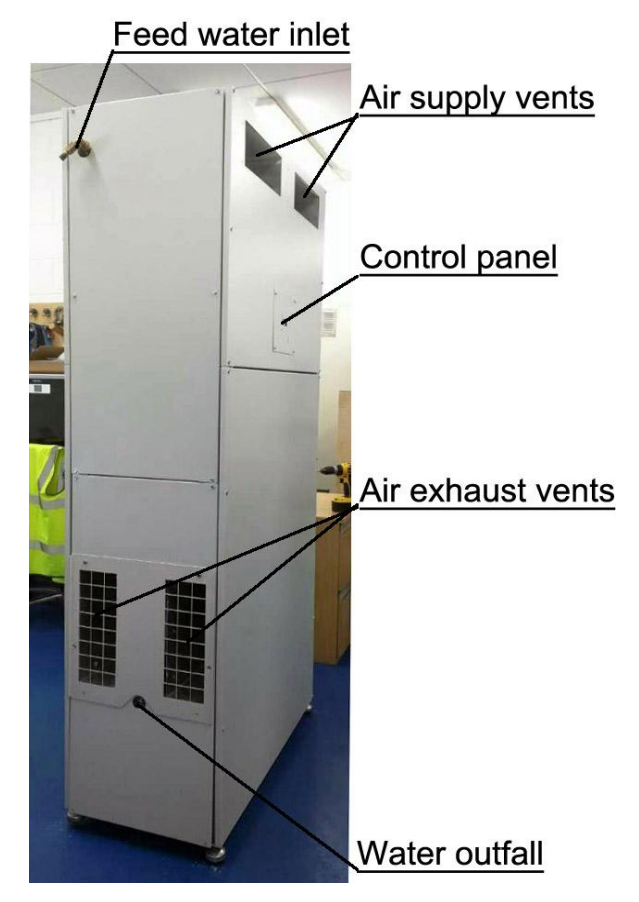

Fig. 8: The 4-kW rated prototype DPC.

During operation, the intake (either outdoor or mixture of the outdoor/indoor) air is initially introduced into the dry channels of the HMX where it loses heat to the neighbourhood wet channels, leading to a certain temperature drop and change of the states from 1 to 2 . At the end of each dry channel, the air is split into two parts: one, namely 'product air (PA)', is delivered to the conditioned space to performe cooling, while the remaining part, namely 'working air', is diverted into the neighbourhood wet channels to cool the dry channel air, with the assistance of water evaporation. Within the wet channels, the working air travels backwards, absorbing heat transported from the dry channel and receiving the moistures evaporated from the surface of the wet channels, thus resulting in continuous temperature and moisture growth of the air and air states change from 2 to 3 . The curve from points 2 to 3 shows a state change of the air within a wet channel. At the initial stage, the temperature of the wet wall is relatively low, which causes the sensible heat transfer from the passing air to the wall, as well as the latent heat transfer resulted from moisture evaporation from the wall to the passing air. When the water stream flows along the wet-wall (from its upward to downward), temperature of the water stream is gradually increasing and at a point of the flow path, water temperature is becoming higher than the pass air temperature. In this case, both the sensible and latent heat transfers are directed to the pass air. For this reason, the air state changing curve (from points 2 to 3 ) is a curve, rather than a straight line, which is derived from the common theoretical analysis. 


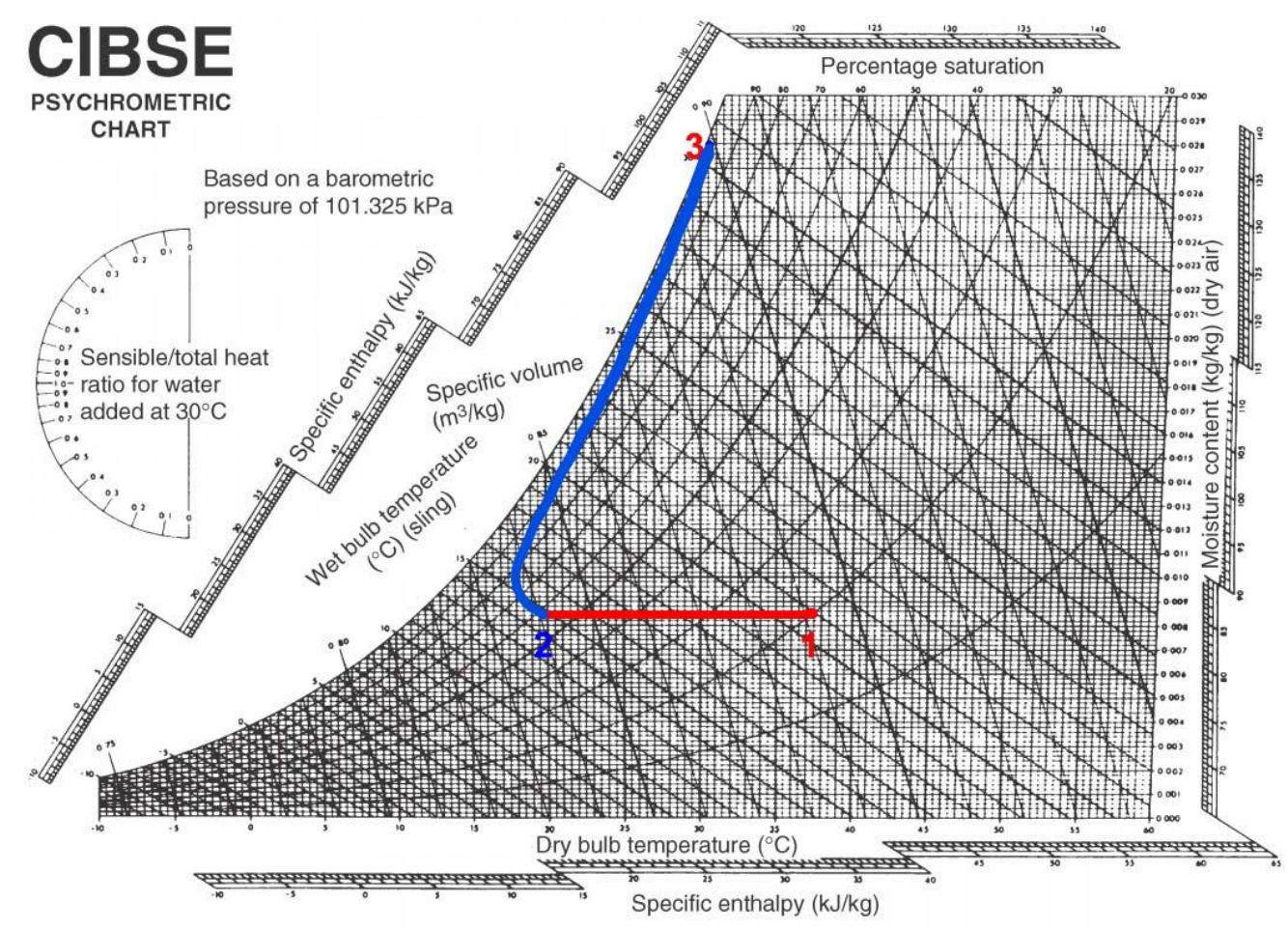

Fig. 9: Illustration of the heat and mass transfer process on psychrometric chart [37].

\section{Experimental testing of the novel prototype DPC}

\subsection{The test rig set up}

To enable accurate parametrical measurement of the 4-kW rated prototype DPC, a dedicated test rig was constructed. This rig, as shown in Fig. 10, comprises an intake air regulating system, supply and discharge air ducting systems, as well as associated measurement instruments that were fitted into the appropriate positions of the duct lines and the cooler interior. The intake air regulating system comprises a high-power electrical heater, a humidifier, a dehumidifier, ducts and dampers, all of which were integrated into a dedicated fan and ducting system to provide a variety of intake air parameters that can simulate various climatic conditions across the world. During operation, the electrical heater, humidifier (or dehumidifier) and dampers in combination created the required temperature and humidity of the intake air, by mixing up the two parts of air (one from the heater and the second from the humidifier (or dehumidifier)) at the right volume flow rate proportion. Meanwhile, the 
auxiliary fan and ducting system was applied to deliver the conditioned air into the cooler and maintain its zero static-pressure status at the inlet of the cooling unit. The technical specifications of the individual components of the intake air regulating system are presented in Table 2. During the testing, the air's parametrical data were obtained from five sets of testing, each taking 5-minute long and average values of the testing data being recorded at steady states.

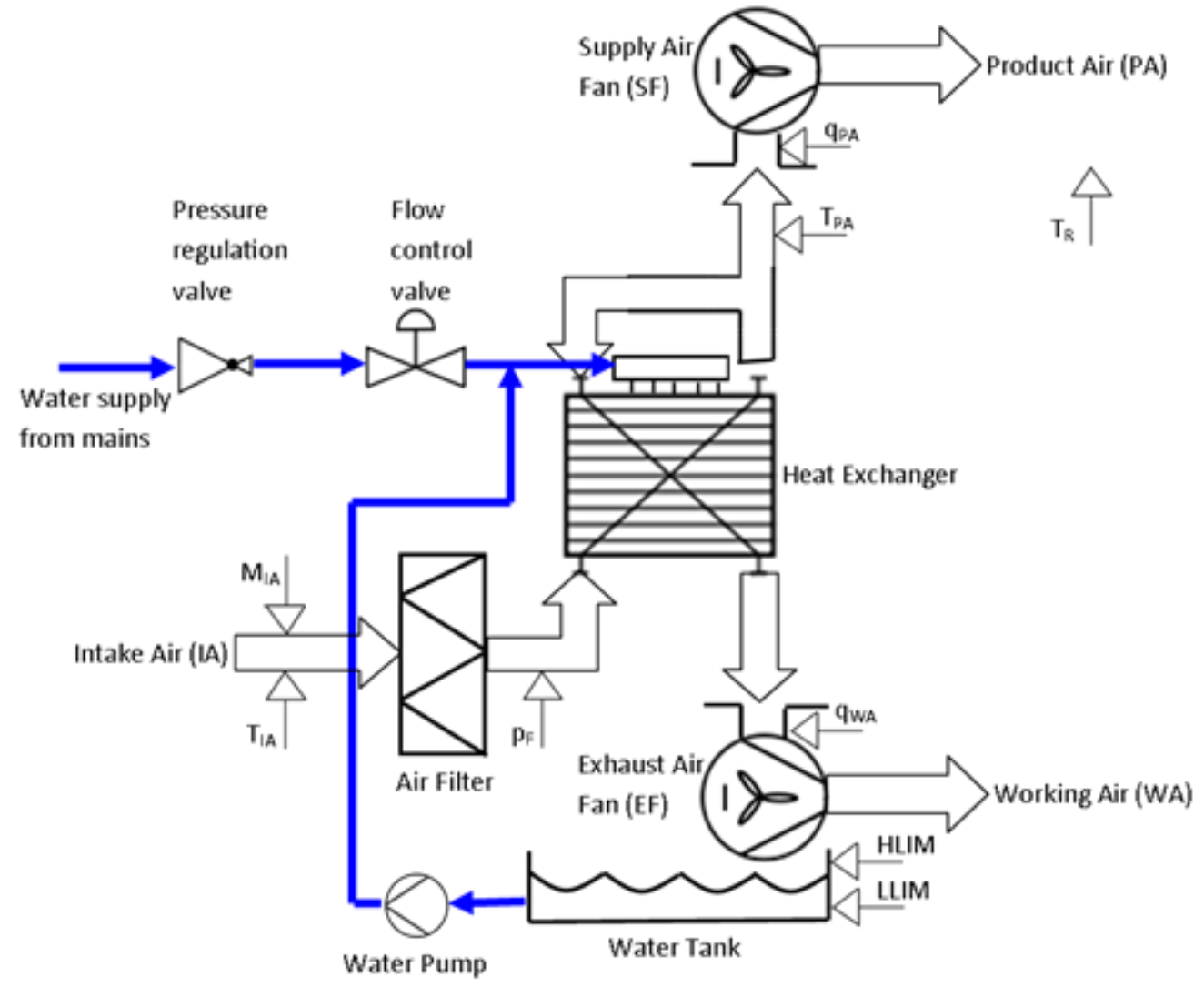

(a) Schematic of testing system 

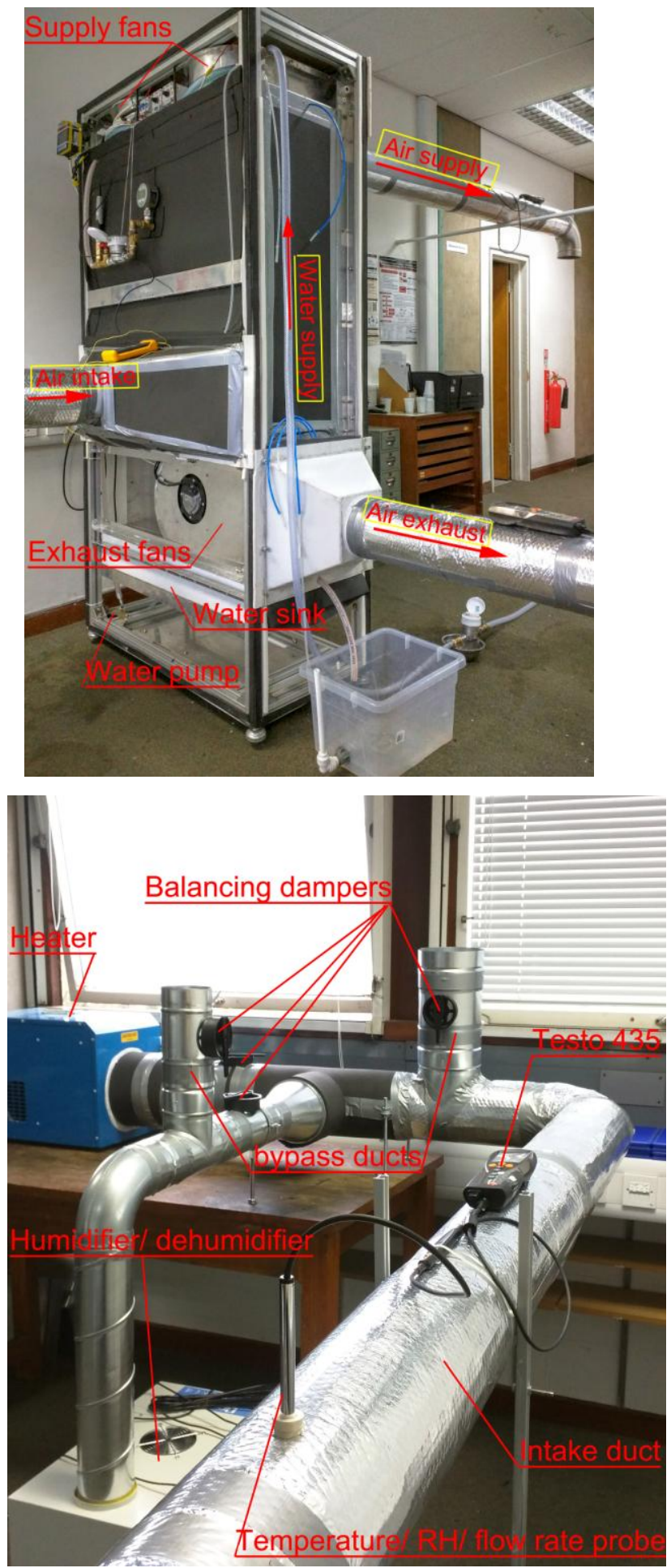

(b) Air and water systems

(c) Intake air regulation system

Fig. 10: The 4-kW rated prototype cooler testing system.

Table 2. Technical specifications of the individual components in the intake air regulation system

\begin{tabular}{|l|l|l|}
\hline Component & Specification & Quantity \\
\hline
\end{tabular}




\begin{tabular}{|l|l|c|}
\hline $\begin{array}{l}\text { Electric heater/ } \\
\text { auxiliary fan }\end{array}$ & $\begin{array}{l}\text { FF13T-13 electric heater } 13.9 \mathrm{~kW}, 16 \mathrm{amp}, \\
415 \mathrm{v}, 3 \text {-phase/ airflow rate } 1017 \mathrm{~m}^{3} / \mathrm{hr}, 400 \mathrm{~Pa}\end{array}$ & 1 \\
\hline Humidifier & DRS-06A 600W, 6kg/hr & 1 \\
\hline Dehumidifier & $\begin{array}{l}\text { Igenix IG9805 Portable Dehumidifier R-410A, } \\
740 \mathrm{~W}-50 \mathrm{~L} / \text { day }(30 \text { and } 80 \% \mathrm{RH})\end{array}$ & 1 \\
\hline Ducting/ fittings & $\begin{array}{l}\text { Spiral steel ducts } \varphi 160, \text { couplings, pressed tees, } \\
\text { reducers with thermal insulation }\end{array}$ & $10 \mathrm{~m}$ \\
\hline Dampers & $\begin{array}{l}\text { Manual balancing dampers with single round } \\
\text { blade and 23 adjustable levels }\end{array}$ & 6 \\
\hline
\end{tabular}

Similar to the intake air regulating system, the combined ducting and auxiliary fan systems were also connected to the supply and discharge air vents of the prototype DPC. These systems were dedicatedly configured to enable accurate measurement of temperature, humidity, and air velocity of the two air streams, by creating a stabilised airflow states at the measurement sections. In particular, the auxiliary fans installed in the two systems were dedicated to compensating the pressure loss resulted from the ducting systems, thus creating the zero static-pressure conditions at the outlets of the discharge and supply air vents. The technical specifications of the individual components of the two systems are presented in

Table 3.

Table 3. Technical specifications of the individual components in the supply and discharge air delivery system

\begin{tabular}{|l|l|l|}
\hline Component & \multicolumn{1}{|c|}{ Specification } & Quantity \\
\hline Ducting/ fittings & $\begin{array}{l}\text { Spiral steel ducts } \varphi 160 \text {, couplings, pressed tees, } \\
\text { reducers with thermal insulation }\end{array}$ & $8 \mathrm{~m}$ each \\
\hline Fan & ebm-papst DC axial fan $-6314 \mathrm{~N} / 2$ TDHHP, $970 \mathrm{~m}^{3} / \mathrm{h}$ & 1 each \\
\hline Dampers & $\begin{array}{l}\text { Manual balancing dampers with single round blade and } \\
23 \text { adjustable levels }\end{array}$ & 1 each \\
\hline
\end{tabular}

Further, specific multi-functional measurement instruments, namely, Testo 435-2 multifunction instrument for VAC (Ventilation and Air Conditioning) \& IAQ (Indoor Air Quality), were installed on the supply, discharge and intake air duct lines for the measurement of the temperature and humidity, while the micro manometers DPM ST650 and auxiliary sample rings were installed on the inlets of the fans to measure the air flow rates across those [38]. 
The positions of the instrument installation were 10 times the duct diameter away from the vents and other local fittings that allowed the establishment of steady airflow at the measurement sections for purpose of accurate reading. Meanwhile, an $A B B$ power meter was used to measure the fan power consumption and a variable DC power supply was applied to measure the power consumption of the water pump. Two water meters were connected to the piping loop to measure the water flow rate supplied to the wet channels of the HMX and the total water consumption by evaporation. A pressure gauge installed at the inlet of the water supplier/distributor was used to monitor water pressure to ensure achieving the optimum pressure of $1.8 \mathrm{mH}_{2} \mathrm{O}$ for even water distribution across the wet surfaces. All the measurement instruments were calibrated prior to their experimental usage. Further, the fan controller was used to adjust the fan speed to obtain different working air ratios and varying cooling capacities. During the measurement, data collected from the above meters were transformed into a computer by USB port. The major instruments for measurement are presented in Table 4.

Table 4. Major measurement instruments for the 4-kW rated prototype DPC

\begin{tabular}{|c|c|c|}
\hline Instrument & Specification & Quantity \\
\hline $\begin{array}{l}\text { Temperature/humidity/ai } \\
\text { r flow rate probe }\end{array}$ & $\begin{array}{l}\text { Testo, thermal velocity probes with built-in temperature and humidity } \\
\text { measurement, } \pm 0.3{ }^{\circ} \mathrm{C}, \pm 2 \% \mathrm{RH}(+2 \text { to }+98 \% \mathrm{RH}), \pm(0.03 \mathrm{~m} / \mathrm{s}+4 \% \text { of mv) }\end{array}$ & 3 \\
\hline $\begin{array}{l}\text { Instrument used with } \\
\text { probe }\end{array}$ & $\begin{array}{l}\text { Testo } 435-2 / 4 \text {-multi-function instrument for VAC \& IAQ, Accuracy } \pm 1 \text { digit, } \\
\pm 0.02 \mathrm{hPa}(0 \text { to }+2 \mathrm{hPa}) \\
\pm 1 \% \text { of mv (remaining range) ; Resolution } 0.1 \% \mathrm{RH}, 0.01 \mathrm{hPa} / 200 \mathrm{hPa}\end{array}$ & 3 \\
\hline Water temperature probe & Testo, waterproof NTC immersion/penetration probe, Accuracy $\pm 0.2^{\circ} \mathrm{C}$ & 2 \\
\hline Air pressure meter & $\begin{array}{l}D P M, \text { ST } 650 \text { micromanometer, Accuracy: } \pm 2 \text { counts (Readings }<100 \\
\text { counts); } \pm 1 \% \text { of reading } \pm 1 \text { count (Readings }>100 \text { counts) }\end{array}$ & 2 \\
\hline Water pressure gauge & $\begin{array}{l}\text { Hangzhou Asmik Sensor Technology Co. Ltd, MIK-Y190, digital pressure } \\
\text { gauge, } 0.4 \% \mathrm{fs}\end{array}$ & 1 \\
\hline Fan power meter & $A B B$, M2M LCD digital power meter, 1 Phase, Accuracy $\pm 0.5 \%$ & 1 \\
\hline Pump power meter & $\begin{array}{l}\text { TTi, EL 155R DC Power supply, 15V 5A, } \\
\text { Resolution: } 10 \mathrm{mV}, 1 \mathrm{~mA} \text {; Accuracy: } 0.3 \% \text { of reading } \pm 3 \text { digits (Voltage } \\
\text { Meter), } 0 \cdot 5 \% \text { of reading } \pm 3 \text { digits (Current Meter) }\end{array}$ & 1 \\
\hline Water meter & Ningbo Amico Inc., LYH-8, 600L/hr, resolution 0.005L & 2 \\
\hline
\end{tabular}

\section{Performance evaluation methods}


The performance of the DPC can be assessed by temperature drop, cooling output, COP, wetbulb effectiveness and dew-point effectiveness. Temperature drop is the temperature difference between the intake air at the dry channel inlet and the PA at the dry channel outlet.

$$
T_{d r o p}=T_{d r y, i n}-T_{d r y, \text { out }}
$$

According to the formula provided by the ASHRAE Standard [39], the cooling output can be expressed as:

$$
Q_{\text {cooling }}=C p\left(T_{d r y, \text { in }}-T_{d r y, \text { out }}\right)(1-\varphi) Q_{m, d r y, \text { in }}
$$

The COP [39] is expressed as the ratio of the cooling output ( $Q_{\text {cooling }}$ ) to the total power consumption $(\mathrm{W})$ of the air cooler, given by:

$$
C O P=\frac{Q_{\text {cooling }}}{W_{\text {fan }}+W_{\text {pump }}}
$$

Wet-bulb cooling effectiveness [40,41] is defined as the ratio of the difference between the inlet and outlet PA temperatures to the difference between the inlet-air's dry bulb and wetbulb temperatures, given by:

$$
\varepsilon_{w b}=\frac{T_{d r y, \text { in }}-T_{d r y, \text { out }}}{T_{d r y, \text { in }}-T_{d r y, \text { in_ }_{-} w}}
$$

(4)

A dew point cooling systems can provide product air with a temperature close to the dew point of the intake air; as such, the dew-point cooling effectiveness [40] is defined as: 


$$
\varepsilon_{d p}=\frac{T_{d r y, \text { in }}-T_{d r y, \text { out }}}{T_{d r y, \text { in }}-T_{d r y, \text { in_dp }}}
$$

\section{Testing processes, results and discussions}

\subsection{Performance test for various climates at the working air ratio of 0.44}

The tests were carried out for various climates at the working air ratio of 0.44 . During the tests, the PA flow rate was adjusted to $750 \mathrm{~m}^{3} / \mathrm{h}$ (corresponding to the $4-\mathrm{kW}$ rated cooling output) and discharge air flow rate to $600 \mathrm{~m}^{3} / \mathrm{h}$, thus yielding a working air ratio of 0.44 .

The idea of using a working air ratio of 0.44 was based on the experimental study of an M30 (Coolerado ${ }^{\circledR}$ USA) DPC; this created the identical operational conditions between our cooler and the M30 product for convenience of performance comparison in between. However, owing to the inevitable minor fluctuation in the outputs of the experimental apparatus, including auxiliary fan, heater and humidifier, the operational condition of the cooler varied slightly in practice. To achieve the relatively accurate results, measurements repeated for five times and the mean values of these measurements were recorded. The error bars relating to these measurements were identified and these are shown in the resultant Figures below, i.e., Figs. 13, 15, 16, 17, 18, 19 and 20 [41].

The tests covered six intake air conditions which represent the design outdoor summer parameters for the cities of Riyadh (Saudi Arabia), Las Vegas (US), Kashi (China), London (UK) and Beijing (China) [42, 43], as well as the Coolerado ${ }^{\circledR}$ M30 testing conditions [44]. In fact, the selected cites represents four different climatic regions [45], i.e. hot \& dry, warm \& dry, warm \& humid and moderate, as shown in Fig. 11. These data and the designed product/exhaust/working air flow rates are presented in Table 5. 
Table 5. Test conditions

\begin{tabular}{|c|c|c|c|c|c|c|}
\hline \multirow{2}{*}{ Location } & \multicolumn{3}{|c|}{ External design conditions } & $\mathbf{P A}$ & EA & \multirow[b]{2}{*}{$\begin{array}{l}\text { Working } \\
\text { air ratio }\end{array}$} \\
\hline & $\begin{array}{l}\mathrm{DB} \\
\left({ }^{\circ} \mathrm{C}\right)\end{array}$ & $\begin{array}{l}\text { WB } \\
\left({ }^{\circ} \mathrm{C}\right)\end{array}$ & $\begin{array}{l}\text { RH } \\
(\%)\end{array}$ & \multicolumn{2}{|c|}{$\begin{array}{l}\text { Flow rate } \\
\qquad\left(\mathrm{m}^{3} / \mathrm{h}\right)\end{array}$} & \\
\hline Coolerado® M30 (US) & 37.8 & 21.1 & 21.7 & \multirow{6}{*}{750} & \multirow{6}{*}{600} & \multirow{6}{*}{0.44} \\
\hline Riyadh, Saudi Arabia & 35.6 & 20.6 & 25.0 & & & \\
\hline Las Vegas, US & 34.8 & 21.9 & 32.2 & & & \\
\hline Kashi, China & 32.1 & 21.0 & 36.9 & & & \\
\hline London, UK & 26.0 & 19.6 & 55.5 & & & \\
\hline Beijing, China & 30.5 & 26.2 & 71.5 & & & \\
\hline
\end{tabular}

DB - Dry bulb temperature, ${ }^{\circ} \mathrm{C}$; WB - Wet bulb temperature, ${ }^{\circ} \mathrm{C} ; \mathrm{RH}$ - Relative humidity, \%; PA — Product air; EA — Exhaust air; Working air ratio-Workingto-intake air ratio.

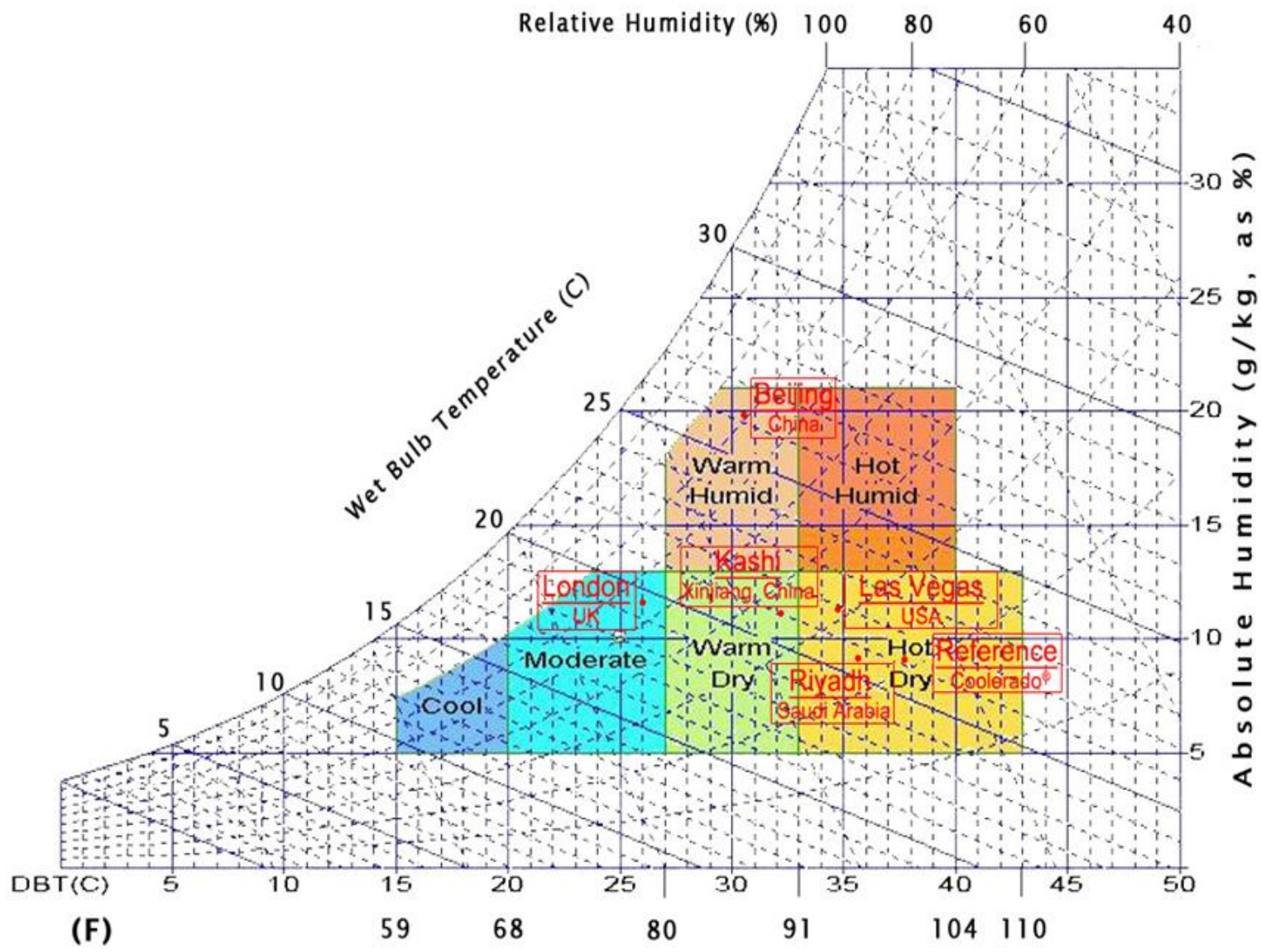

Fig. 11: Climate characters on the psychrometric chart. 
The testing results are shown in Table 6 and Fig. 12. Table 6 presents the parametrical data of the tested system, including those for the PA temperature, temperature drop, cooling output, COP, wet-bulb and dew-point effectiveness, EA relative humidity (RH) as well as the system power consumption. For all these tests, the wet-bulb effectiveness was in the range of $100 \%-109.8 \%$ and the dew-point effectiveness was in the range of $67 \%-76.3 \%$, while the EA relative humidity ( $\mathrm{RH})$ was as high as $90.7 \%-94.3 \%$, indicating that the water evaporation within the wet channels was effective that led to the approximately saturated discharge air at the outlet.

Fig. 12 shows a comparison among the testing results (COP, cooling capacity and temperature drop) for six simulated intake air conditions that represent the aforementioned climates. It is clear that the dryer intake air with a lower relative humidity led to a higher air temperature drop, as well as the higher cooling output and COP. The order of the cooler performance from high to low corresponded to the rank of the following test conditions: (1) the Coolerado $^{\circledR}$ M30; (2) Riyadh; (3) Las Vegas; (4) Kash; (5) London; and (6) Beijing. As shown in Table 6, this rank was in consistent with the order of the intake air humidity from low to high. The highest performance, occurring under the Coolerado ${ }^{\circledR}$ M30 testing condition (hot \& dry), presented a temperature drop of $17.1^{\circ} \mathrm{C}$, cooling output of $4.2 \mathrm{~kW}$ and COP of 37.4; while the lowest performance occurred in Beijing climate (warm \& humid), with a temperature drop of $4.5^{\circ} \mathrm{C}$, cooling capacity of $1.1 \mathrm{~kW}$ and COP of 9.7.

Table 6 Testing results

\begin{tabular}{|c|c|c|c|c|c|c|c|c|c|}
\hline Location & $\begin{array}{c}\mathbf{T p} \\
\left({ }^{\circ} \mathrm{C}\right)\end{array}$ & $\begin{array}{l}\text { Td } \\
\left({ }^{\circ} \mathrm{C}\right)\end{array}$ & $\begin{array}{c}\text { Cooling } \\
\text { capacity } \\
(\mathbf{k W})\end{array}$ & $\begin{array}{c}\text { COP } \\
(-)\end{array}$ & $\begin{array}{c}\text { Wet }_{\text {eff }} \\
(-)\end{array}$ & $\begin{array}{c}\text { Dew }_{\text {eff }} \\
(-)\end{array}$ & $\begin{array}{c}\text { Fans } \\
\text { power } \\
(W)\end{array}$ & $\begin{array}{c}\text { RH of } \\
\text { EA } \\
(-)\end{array}$ & $\begin{array}{c}\text { Pump } \\
\text { power } \\
(W)\end{array}$ \\
\hline Coolerado® & 20.8 & 17.1 & 4.25 & 37.4 & $102.4 \%$ & $67.1 \%$ & 112 & $94.3 \%$ & \\
\hline Riyadh & 20.7 & 14.9 & 3.66 & 32.2 & $107.2 \%$ & $72.0 \%$ & 112 & $92.2 \%$ & \\
\hline Las Vegas & 20.4 & 14.5 & 3.56 & 31.3 & $109.8 \%$ & $74.4 \%$ & 112 & $92.9 \%$ & 1.56 \\
\hline Kashi & 20.3 & 11.8 & 2.89 & 25.5 & $106.3 \%$ & $71.1 \%$ & 112 & $91.0 \%$ & \\
\hline London & 19.8 & 6.1 & 1.5 & 13.2 & $100.0 \%$ & $67.0 \%$ & 112 & $90.7 \%$ & \\
\hline
\end{tabular}




\begin{tabular}{|c|c|c|c|c|c|c|c|c|}
\hline Beijing & 26.0 & 4.5 & 1.1 & 9.7 & $102.3 \%$ & $76.3 \%$ & 112 & $92.0 \%$ \\
\hline \multicolumn{9}{|c|}{$\mathrm{Tp}$ - product air temperature; $\mathrm{Td}$ - temperature drop; $\mathrm{Wet}_{\mathrm{eff}}-$ Wet bulb effectiveness; } \\
\hline \multicolumn{9}{|c|}{ Dew $_{\text {eff }}$ Dew point effectiveness; RH—Relative humidity; EA—Exhaust air. } \\
\hline
\end{tabular}

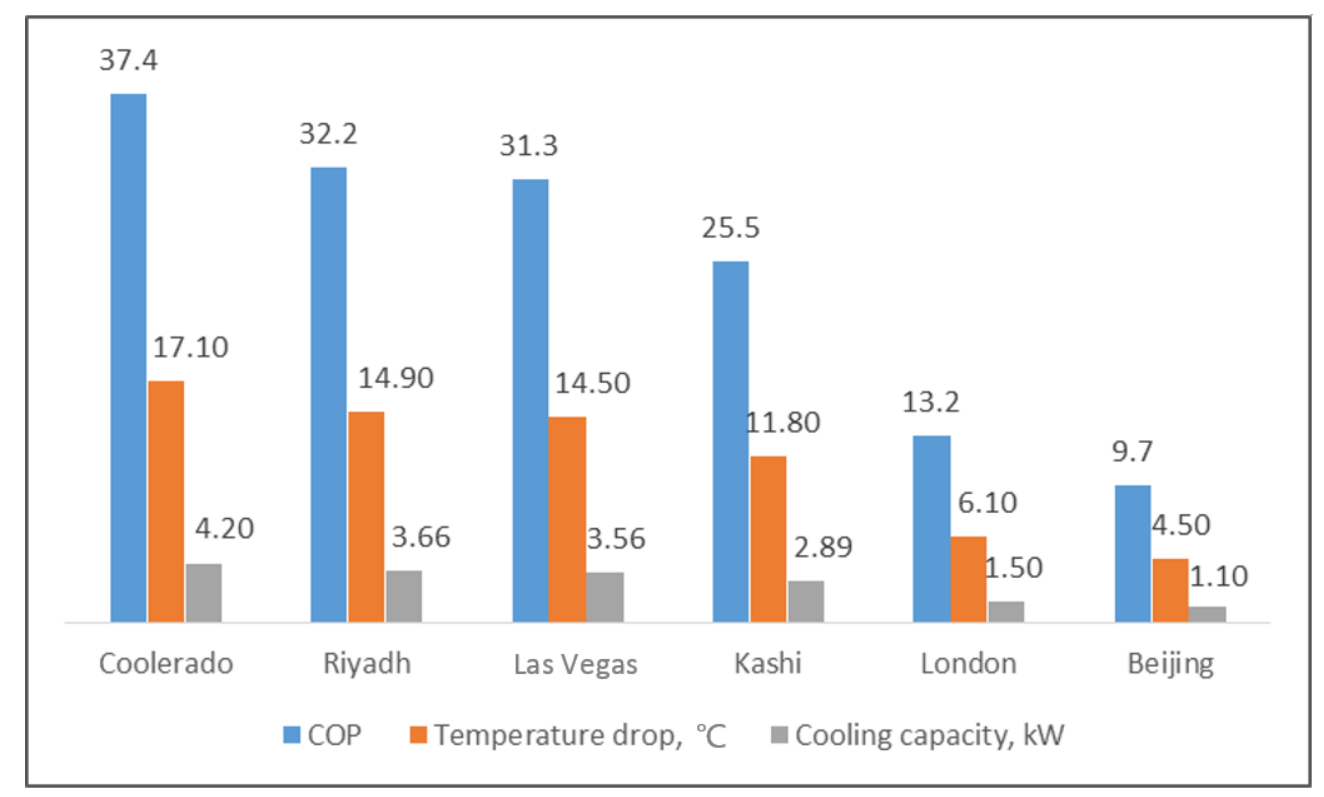

Fig. 12: Temperature drop and cooling capacity of the cooler at various climatic conditions, with the working air ratio of 0.44 .

\subsection{Identification of the optimum working air ratio}

The working air ratio is defined as the ratio of the exhaust air to the total intake air. The increased working air ratio leads to the decreased PA flow rate and increased temperature drop of the intake air within the DPC. As the cooling output of a DPC is the product of the air temperature drop and its flow rate, an optimum working air ratio would be in existence that can create the highest cooling output.

The tests were dedicated to identifying the optimum working air ratio of the prototype DPC. The intake air conditions for the tests were set to be exactly same as that for the Coolerado ${ }^{\circledR}$ 
M30 testing conditions, i.e. $37.8^{\circ} \mathrm{C}$ of dry bulb temperature and $21.1^{\circ} \mathrm{C}$ of coincident wet bulb temperature. With the fixed PA flow rate of $750 \mathrm{~m}^{3} / \mathrm{h}$, a range of working air flow rates were selected to obtain different working air ratios. Comparison among the test results under various working air ratios was undertaken, indicating that the optimum working air ratio was 0.364 , at which the cooler achieved the highest cooling output.

Fig. 13 shows the variation of the temperature drop and cooling capcaity of the cooler at different working air ratios. It was found that at the optimum working air ratio of 0.364 , the cooler achieved the maximum temperature drop of $19.1^{\circ} \mathrm{C}$ and cooling output of $4.75 \mathrm{~kW}$. With the working air ratio increasing from 0.364 to 0.445 , the temperature drop kept falling. Inversely, with the working air ratio increasing from 0.268 to 0.364 , the temperature drop continued to grow. This indicated that at the optimum working air ratio of 0.364 , the water evaporation within the wet channels achieved the maximum that led to the best cooling effect of the cooler. As shown in Fig. 14, increasing the working air ratio led to the decrease in the $\mathrm{RH}$ of the exhaust air. This again indicated that the optimum working air ratio was 0.364 .

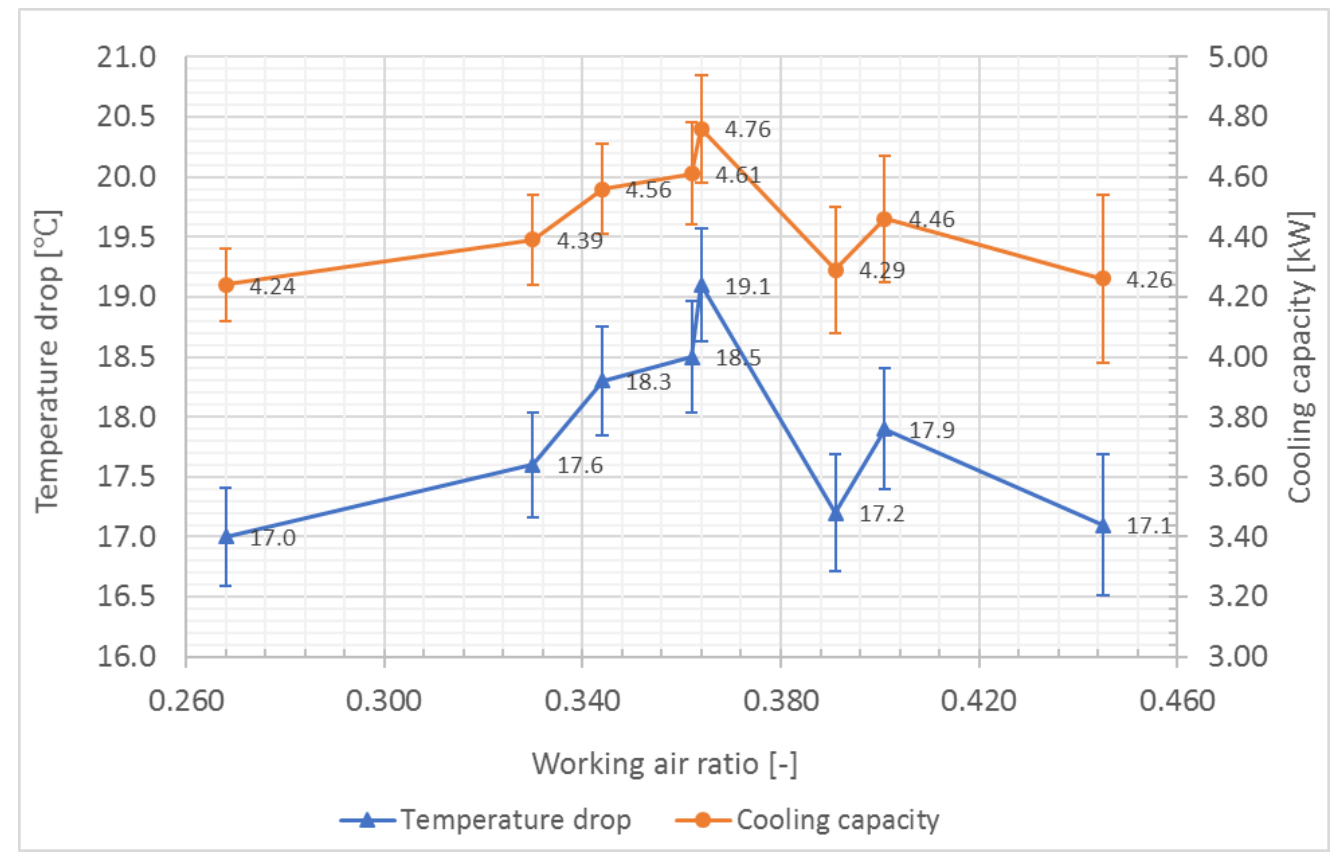

Fig. 13: Variations of the temperature drop and cooling output with the working air ratio. 


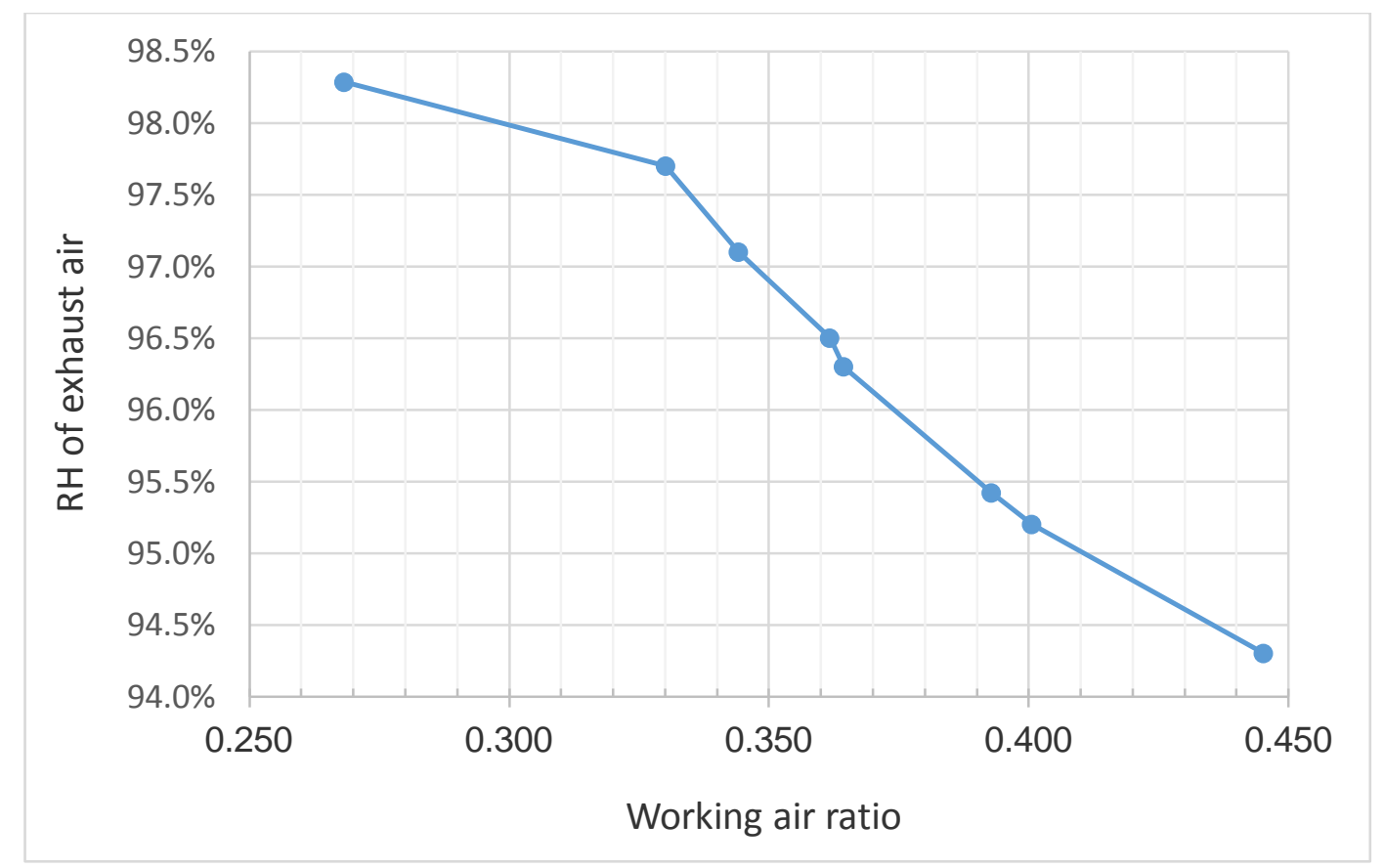

Fig. 14: RH of exhaust air at different working air ratio.

\subsection{Performance comparison between the prototype and the M30 DPC}

Based on the above tests, a comparison between the prototype's performance data and that of the M30 (Coolerado ${ }^{\circledR}$, US) is presented in Table 7. It is seen that under the Coorlerado ${ }^{\circledR}$ M30 intake air conditions (i.e., dry bulb temperature of $37.8^{\circ} \mathrm{C}$ and coincident wet bulb temperature of $21.1^{\circ} \mathrm{C}$ ) and working air ratio of 0.44 , the prototype cooler obtained a lower PA temperature $\left(20.8^{\circ} \mathrm{C}\right.$ vs. $\left.21.5^{\circ} \mathrm{C}\right)$, higher $\mathrm{COP}(37.4$ vs. 18.4$)$ and higher wet-bulb effectiveness (102.4\% vs. 93\%). The cooling output of the prototype cooler was also slightly higher $(4.25 \mathrm{~kW}$ vs. $4.15 \mathrm{~kW})$ despite its PA flow rate $\left(750 \mathrm{~m}^{3} / \mathrm{h}\right)$ was slightly lower than that of the M30 $\left(765 \mathrm{~m}^{3} / \mathrm{h}\right)$.

Table 7. Comparison of the prototype cooler with the M30 product

\begin{tabular}{|c|c|c|c|c|c|c|c|c|}
\hline Cooler & $\begin{array}{c}\text { PA } \\
\text { flow rate } \\
\left(\mathrm{m}^{3} / \mathrm{h}\right)\end{array}$ & $\begin{array}{c}\text { Working } \\
\text { air ratio } \\
(-)\end{array}$ & $\begin{array}{c}\text { Cooling } \\
\text { capacity } \\
(\mathbf{k W})\end{array}$ & $\begin{array}{c}\text { PA } \\
\text { temperature } \\
\left({ }^{\circ} \mathrm{C}\right)\end{array}$ & $\begin{array}{c}\text { COP } \\
(-)\end{array}$ & $\begin{array}{c}\text { Dew }_{\text {eff }} \\
(-)\end{array}$ & $\begin{array}{c}\text { Fan } \\
\text { power } \\
(W)\end{array}$ & $\begin{array}{c}\text { Pump } \\
\text { power } \\
(W)\end{array}$ \\
\hline M30 & 765 & 0.441 & 4.15 & 21.5 & 18.4 & $93.0 \%$ & 450 & \multirow{3}{*}{1.56} \\
\hline \multirow[b]{2}{*}{ Prototype } & \multirow{2}{*}{750} & 0.441 & 4.25 & 20.8 & 37.4 & $102.4 \%$ & 112 & \\
\hline & & 0.364 & 4.75 & 18.8 & 52.5 & $114.4 \%$ & 89 & \\
\hline
\end{tabular}


Comparison between the two different working air ratios (i.e. 0.364 and 0.441) indicated that the prototype cooler achieved the higher cooling output and COP at the working air ratio of 0.364. At this ratio, a lower PA temperature (i.e., $18.8^{\circ} \mathrm{C}$ ), a higher wet-bulb effectiveness (i.e., 114.4\%) and a higher cooling capacity (i.e., $4.75 \mathrm{~kW}$ ) were achieved. It should be particularly noted that the prototype cooler achieved an extremely high COP (52.5), which was largely owing to the lower energy consuming fan $(89 \mathrm{~W}$ under the specified operational condition).

\subsection{Performance test under various intake air conditions at the optimum working air ratio of 0.364}

Based on the identified optimum working air ratio of 0.364 , tests were carried out under various intake air conditions in order to assess the performance of the cooler. The working air ratio of 0.364 corresponds to the EA flow rate of $429 \mathrm{~m}^{3} / \mathrm{h}$ for the designed PA flow rate of $750 \mathrm{~m}^{3} / \mathrm{h}$. The other conditions for the tests were the same as those addressed in Section 5.1. The test results, as presented in Table 7, were compared with those obtained from the tests in Section 5.1, in which a working air ratio of 0.44 was emploied. It was found that all the results at the ratio of 0.364 , including temperature reduction, cooling output, $\mathrm{COP}$ and dewpoint and wet-bulb effectivenesses, were superior to those at the ratio of 0.44 . During this group of tests, a smaller fan power of $89 \mathrm{~W}$ was required compared to that at the ratio of 0.44 (i.e. $112 \mathrm{~W}$ ), owing to the decreased EA flow rate. The increased cooling output and decreased fan power consumption led to the significantly higher COP compared to those at working air ratio of 0.44 .

Table 7. Higher performance obtained at the optimal working air ratio of 0.364 under various intake air conditions

\begin{tabular}{|c|c|c|c|c|c|c|c|c|c|c|c|c|}
\hline \multirow[b]{2}{*}{ Working air ratio } & \multicolumn{2}{|c|}{$\begin{array}{c}\text { Temp. drop } \\
\left({ }^{\circ} \mathrm{C}\right)\end{array}$} & \multicolumn{2}{|c|}{$\begin{array}{c}\text { Cooling output } \\
\qquad(\mathrm{kW})\end{array}$} & \multicolumn{2}{|c|}{$\begin{array}{c}\text { COP } \\
(-)\end{array}$} & \multicolumn{2}{|c|}{ Wet $_{\text {eff }}$} & \multicolumn{2}{|c|}{ Dew $_{\text {eff }}$} & Fan power & D) \\
\hline & 0.44 & 0.364 & 0.44 & 0.364 & 0.44 & 0.364 & 0.44 & 0.364 & 0.44 & 0.364 & 0.44 & 0.364 \\
\hline
\end{tabular}




\begin{tabular}{|l|c|c|c|c|c|c|c|c|c|c|c|c|}
\hline Coolerado $^{\circledast} \mathrm{M} 30$ & 17.1 & 19.1 & 4.3 & 4.8 & 37.4 & 52.5 & 102 & 114 & 67 & 75 & & \\
\hline Riyadh & 14.9 & 16.6 & 3.7 & 4.2 & 32.2 & 46.2 & 107 & 114 & 72 & 75 & \\
\hline Las Vegas & 14.5 & 14.6 & 3.6 & 3.7 & 31.3 & 40 & 110 & 112 & 74 & 76 & \\
\hline Kashi & 11.8 & 12.7 & 2.9 & 3.2 & 25.5 & 35.3 & 106 & 115 & 71 & 77 & 89 \\
\hline London & 6.1 & 6.3 & 1.5 & 1.8 & 13.2 & 18.1 & 100 & 104 & 67 & 69 \\
\hline Beijing & 4.5 & 5.9 & 1.1 & 1.5 & 9.7 & 16.5 & 102 & 128 & 76 & 95 & & \\
\hline
\end{tabular}

\subsection{Cases for different cooling outputs at the optimum working air ratio of 0.364}

For each set of intake air condition (i.e. those for Coolerado ${ }^{\circledR}$ M30, Riyadh, Las Vegas, Kashi, London and Beijing), tests were carried out in a range of PA flow rates from 510 - 760 $\mathrm{m}^{3} / \mathrm{h}$ to obtain its cooling outputs at the optimum working air ratio of 0.364 . The results indicated that for all climates, the performance parameters of the cooler, including temperature drop, COP, wet-bulb effectiveness and dew point effectiveness, decreased with increasing PA flow rate, while the cooling output increased. A range of test results, i.e. results under the climates of Riyadh (Saudi Arabia), Kashi (China) and London (UK), are discussed as follows.

\section{$\underline{\text { Riyadh, Saudi Arabia }}$}

The design summer outdoor air condition for Riyadh is $35.6^{\circ} \mathrm{C}$ of dry bulb temperature and $20.6^{\circ} \mathrm{C}$ of the coincident wet bulb temperature. Under this inlet air condition, the variations of the temperature drop and cooling output with the PA flow rate were tested and the results were plotted in Fig. 15. It was found that when the PA flow rate increased from $513 \mathrm{~m}^{3} / \mathrm{h}$ to $758 \mathrm{~m}^{3} / \mathrm{h}$, the cooling output of the cooler increased from $3.0 \mathrm{~kW}$ to $4.2 \mathrm{~kW}$ and the temperature drop fell from $17.8^{\circ} \mathrm{C}$ to $16.6^{\circ} \mathrm{C}$. The variations of the $\mathrm{COP}$ and cooling effectiveness with the PA flow rate were shown in Fig. 16, indicating that when the PA flow rate increased from $513 \mathrm{~m}^{3} / \mathrm{h}$ to $758 \mathrm{~m}^{3} / \mathrm{h}$, the COP had a quick fall from 69.3 to 46.2 , while 
the wet-bulb effectiveness and dew-point effectiveness had slight fall from $120.5 \%$ to $114.0 \%$ and from $78.7 \%$ to $75.1 \%$ respectively.

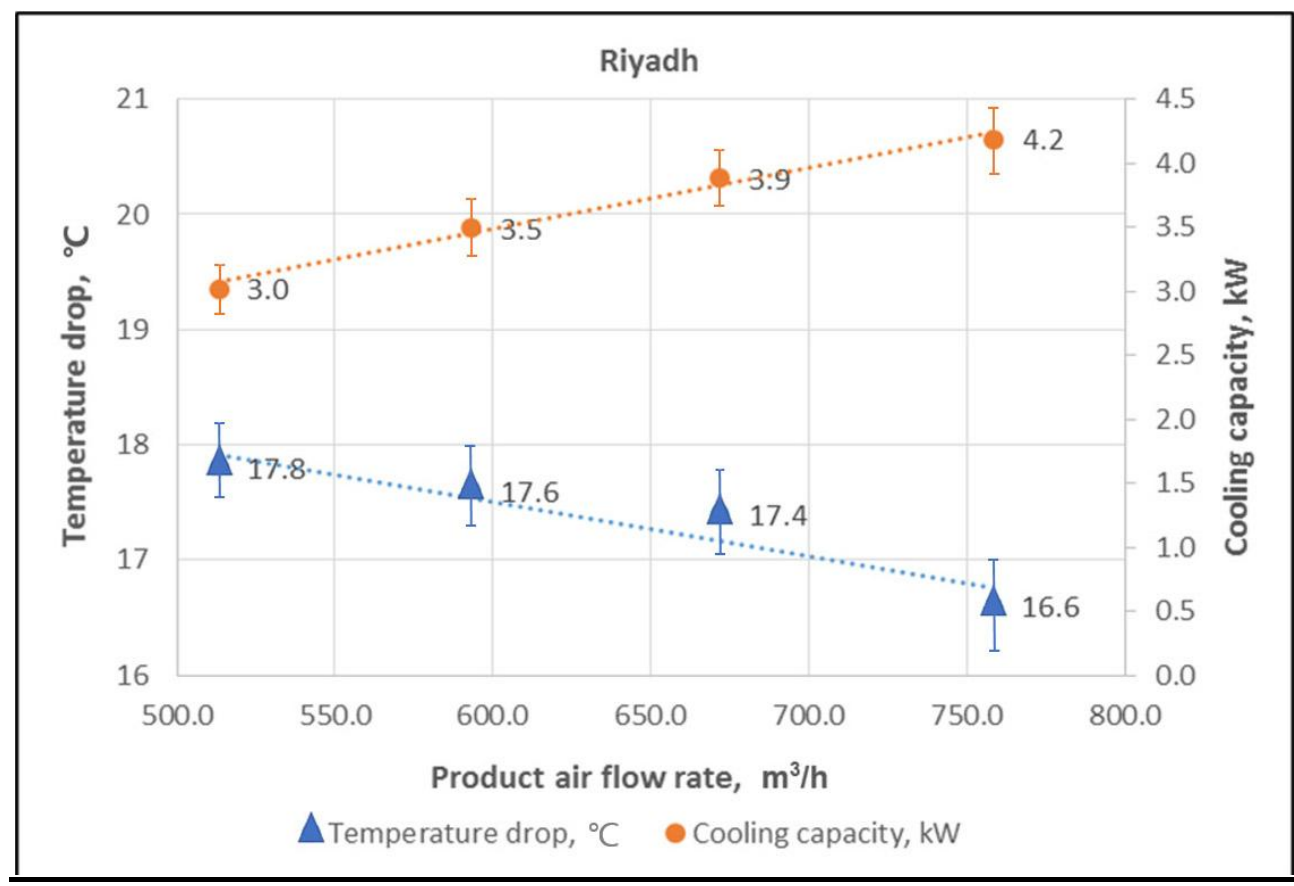

Fig. 15: Temperature and cooling capacity vs. PA flow rate (Riyadh).

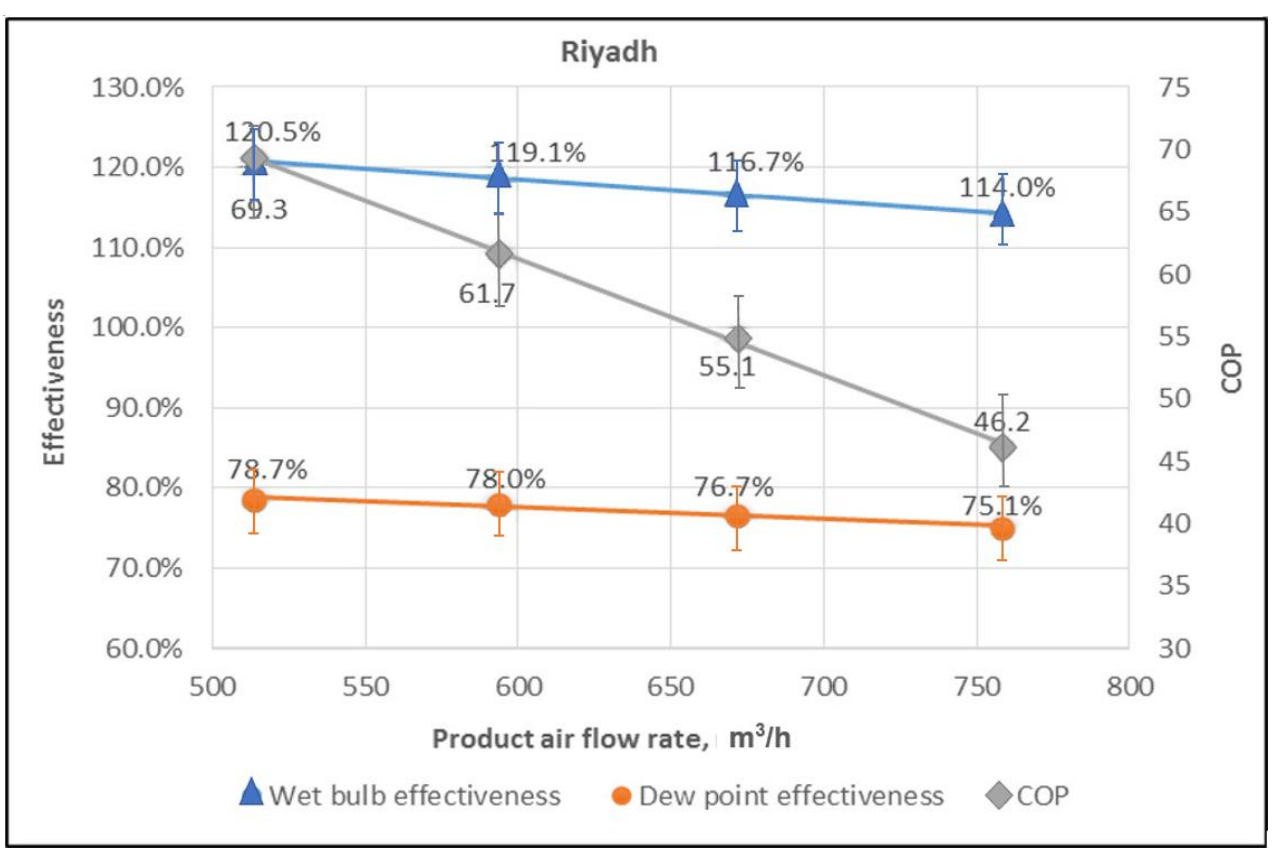

Fig. 16: Effectiveness and COP vs PA flow rate (Riyadh). 


\section{$\underline{\text { Kashi, China }}$}

The design summer outdoor air condition for Kashi is $32.1^{\circ} \mathrm{C}$ of dry bulb temperature and $21.0^{\circ} \mathrm{C}$ of the coincident wet bulb temperature. Under this inlet air condition, the variations of the temperature drop and cooling output with the PA flow rate were experimentally investigated and the results are shown in Fig. 17. It was found that when the PA flow rate increased from $512 \mathrm{~m}^{3} / \mathrm{h}$ to $756 \mathrm{~m}^{3} / \mathrm{h}$, the cooling output increased from $2.3 \mathrm{~kW}$ to $3.2 \mathrm{~kW}$ and the temperature drop fell slightly from $13.3^{\circ} \mathrm{C}$ to $12.7^{\circ} \mathrm{C}$. The variations of the COP and cooling effectiveness with the PA flow rate were shown in Fig. 18. When the PA flow rate increased from $512 \mathrm{~m}^{3} / \mathrm{h}$ to $756 \mathrm{~m}^{3} / \mathrm{h}$, the COP had a significant fall from 52.1 to 35.3 , while the wet-bulb and dew-point effectiveness fell slightly from $119.7 \%$ to $114.7 \%$ and from $80.6 \%$ to $77.0 \%$ respectively.

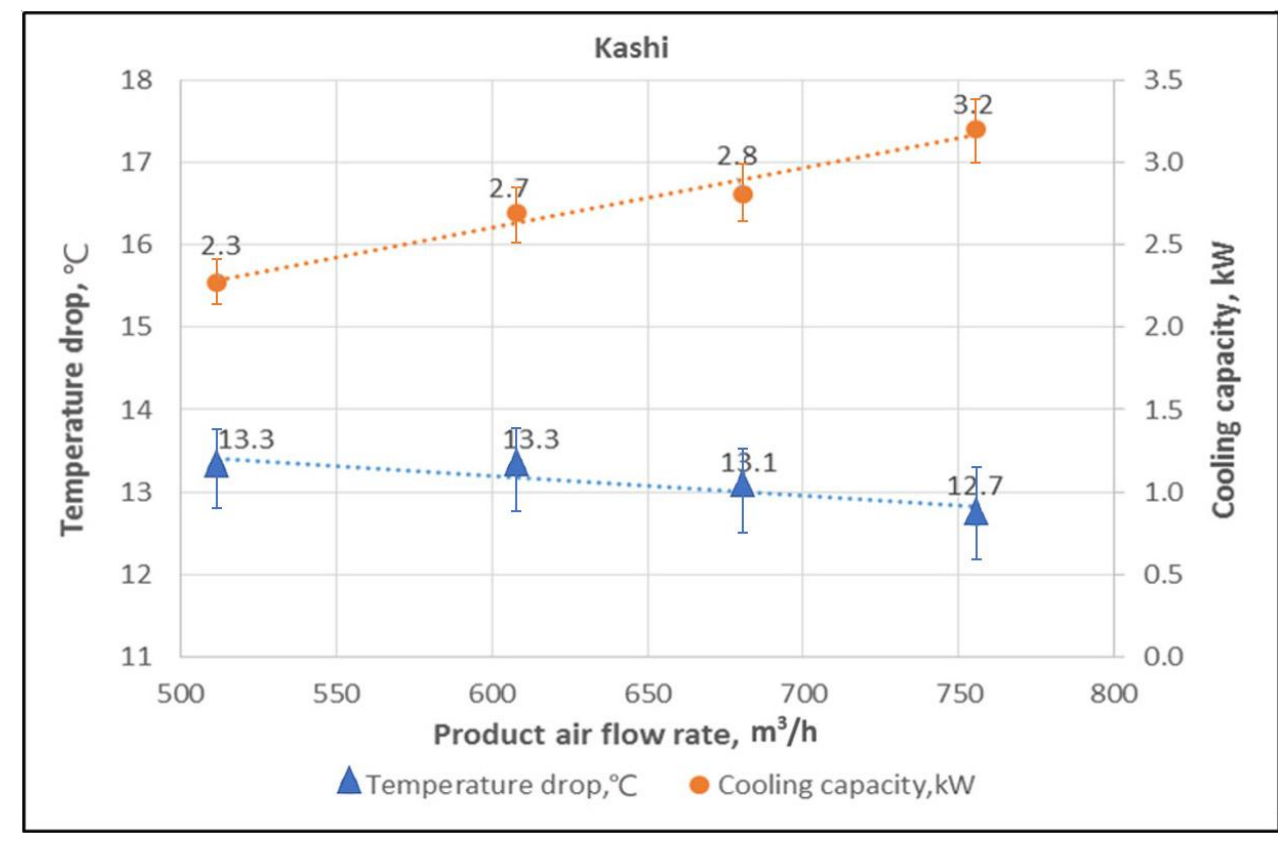

Fig. 17: Temperature and cooling capacity vs. PA flow rate (Kashi). 


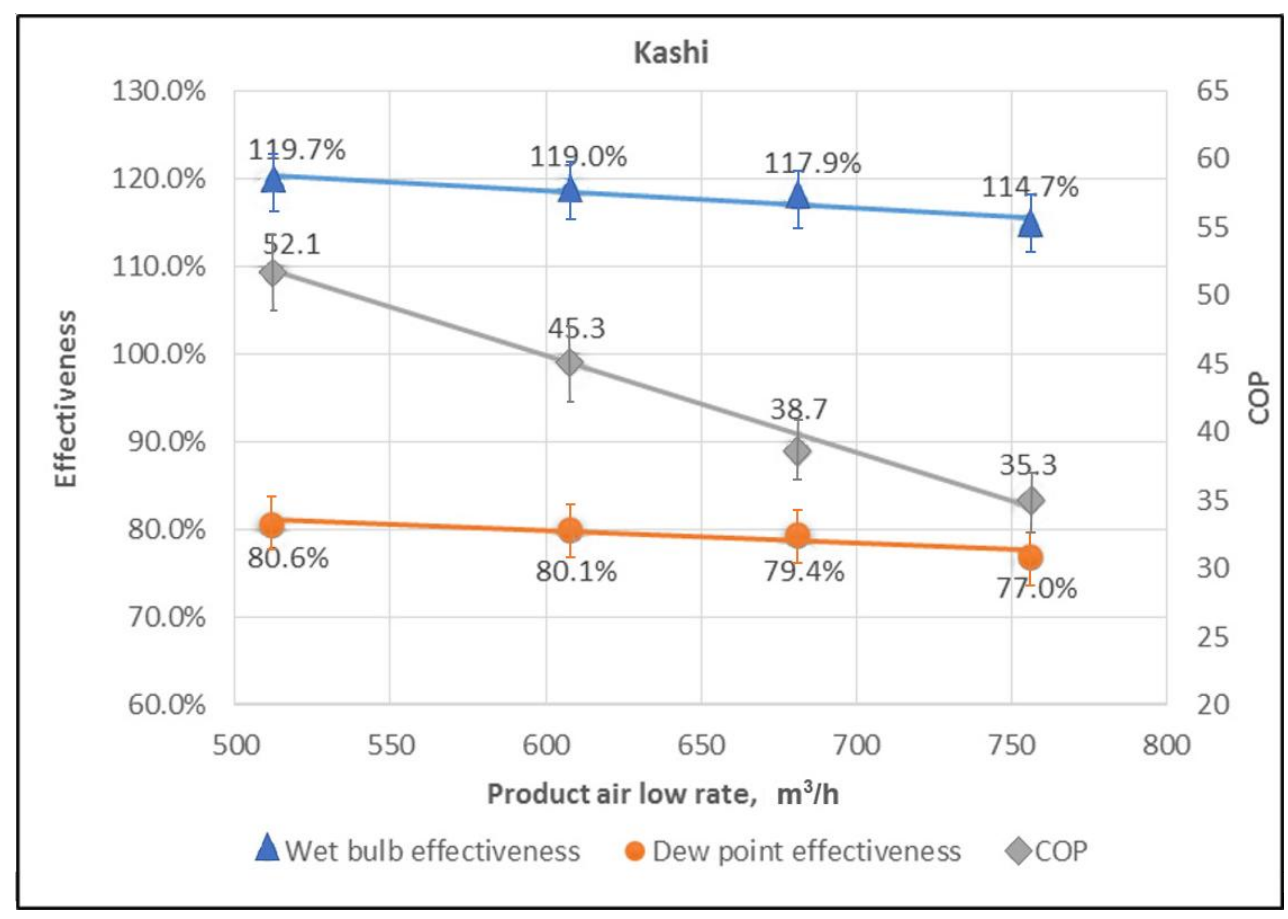

Fig. 18: Effectiveness and COP vs. PA flow rate (Kashi).

\section{London, UK}

The design summer outdoor air condition is $26^{\circ} \mathrm{C}$ of dry bulb temperature and $19.6^{\circ} \mathrm{C}$ of the coincident wet bulb temperature. Under this inlet condition, the variations of the temperature drop and cooling output with the PA flow rate were experimentally investigated and the results are presented in Fig. 19. It was found that when the PA flow rate increased from 526 $\mathrm{m}^{3} / \mathrm{h}$ to $750 \mathrm{~m}^{3} / \mathrm{h}$, the cooling output had a measurable growth from $1.4 \mathrm{~kW}$ to $1.8 \mathrm{~kW}$, and the temperature drop had a slight fall from $7.7^{\circ} \mathrm{C}$ to $6.3^{\circ} \mathrm{C}$. The variations of the COP and cooling effectiveness with the PA flow rate were shown in Fig. 20. When the PA flow rate increased from $526 \mathrm{~m}^{3} / \mathrm{h}$ to $750 \mathrm{~m}^{3} / \mathrm{h}$, the COP had a significant fall from 29.7 to 18.1 , and the wet-bulb and dew-point effectiveness had the slight from $119.5 \%$ to $104.0 \%$ and from $79.4 \%$ to $69.0 \%$, respectively. 


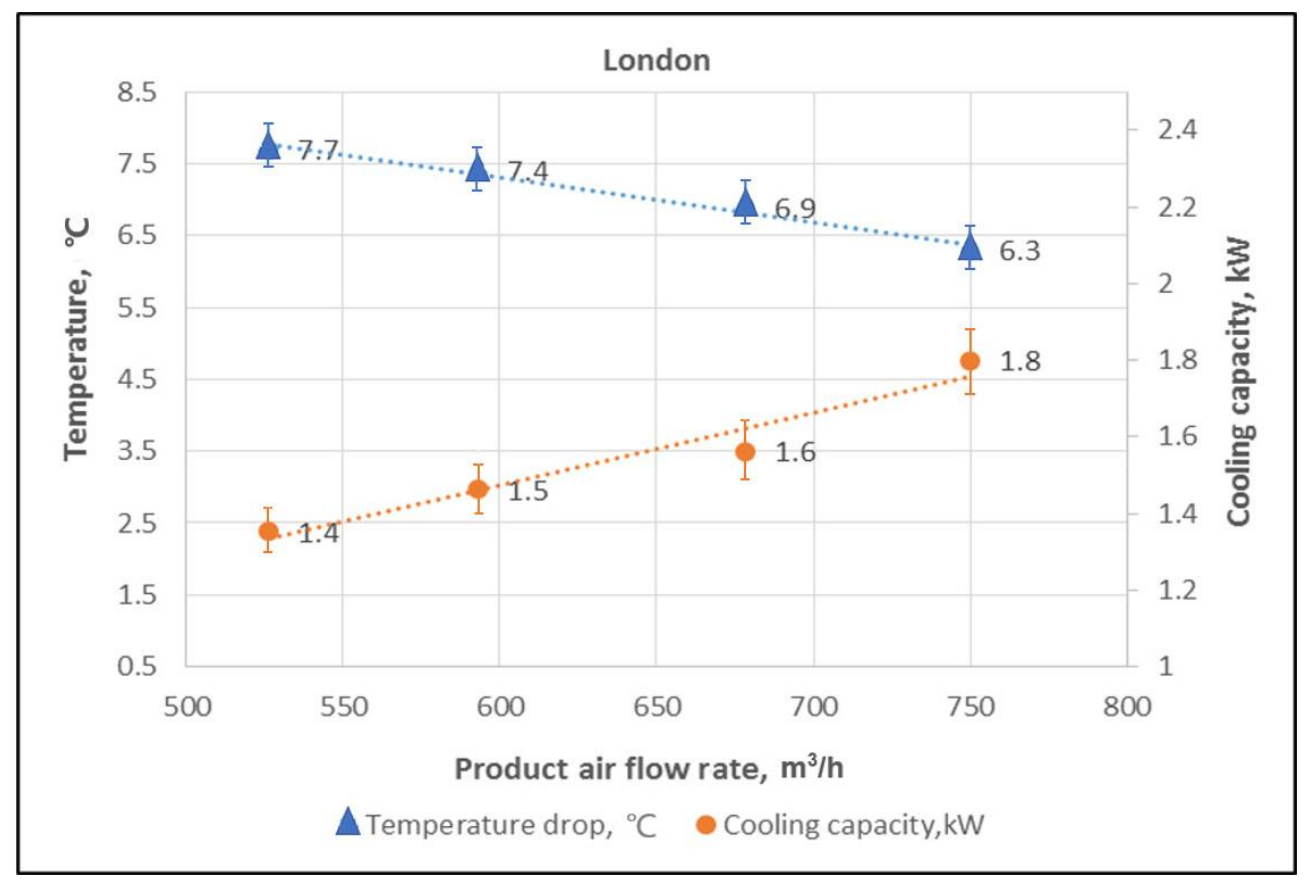

Fig. 19: Temperature and cooling capacity vs. PA flow rate (London).

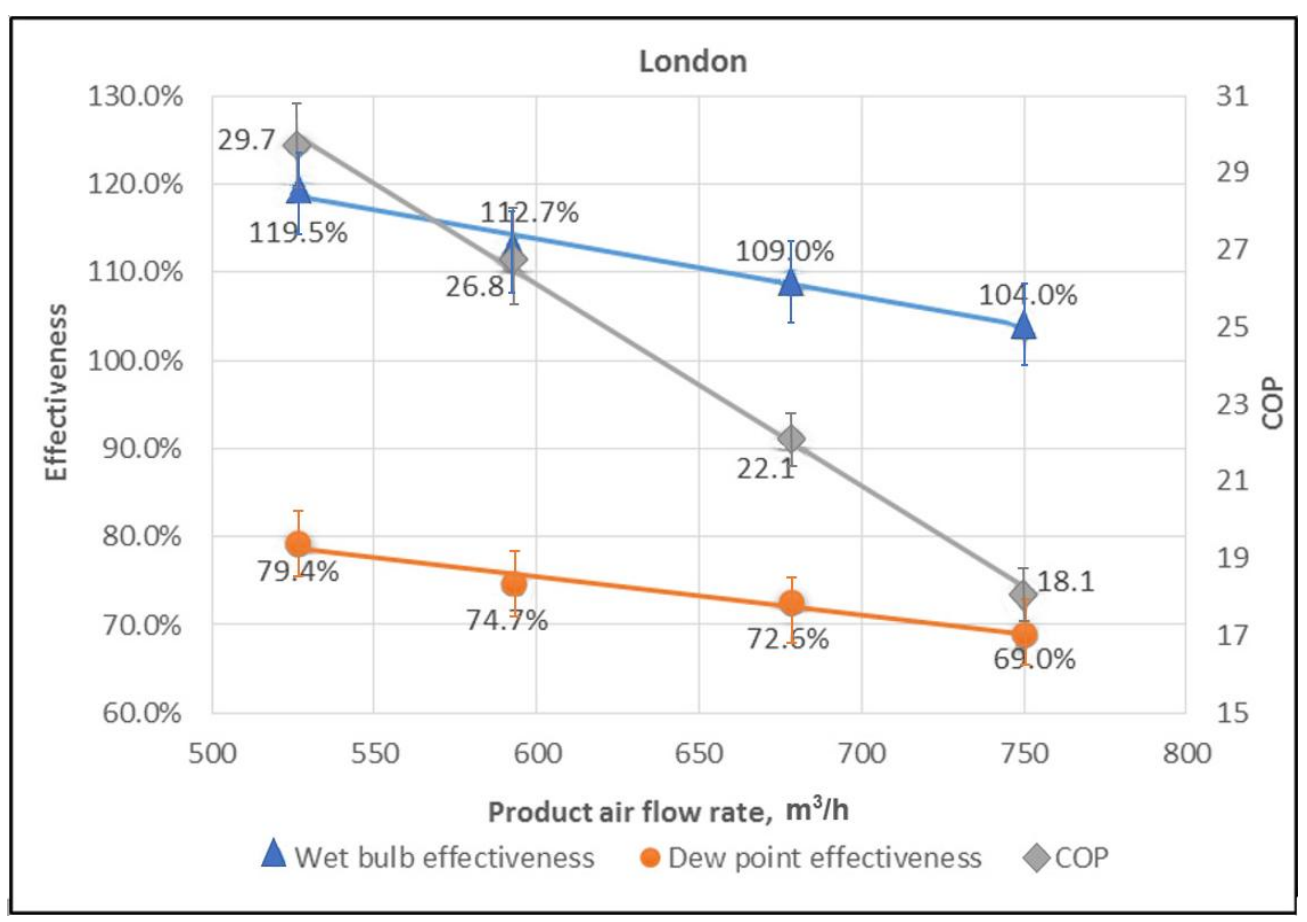

Fig. 20: Effectiveness and COP vs. PA flow rate (London).

It is clear that under a dryer intake air conditions the cooler demonstrated a higher cooling and energy performance. Of the simulated intake air conditions that represent the climates of 
six different cities in the world, the cooler presented the best energy performance under hot \& dry climate (Riyadh), followed by warm \& dry (Kashi) and moderate (London) climates.

\section{Conclusions}

A novel dew point cooler employing super-performance wet material layer, complex HMX and intermittent water supply scheme was experimentally investigated. This created the enhanced wet ability of the wet channel surface, reduced water pump power consumption, increased heat transfer area and consequently increased heat transfer rate, as well as decreased air flow resistance. This paper presented the design, construction and experimental testing of a 4-kW rated prototype, under a range of inlet air conditions that can represent different climates in the world. Based on the test results, the energy and cooling performances of such a kind of cooler were assessed compared to existing dew point air coolers on market.

Initial tests were carried out under six inlet air conditions with a working air ratio of 0.44 . It was found that the cooler had the wet-bulb effectiveness in the range 100\%-109.8\% and the dew-point effectiveness in the range 67\%-76.3\%, depending upon the climatic conditions applied. During the tests, the EA relative humidity $(\mathrm{RH})$ reached $90.7 \%-94.3 \%$, indicating that the water evaporation within the wet channels took place effectively and the exhaust air could eventually reach the saturation state at the outlet of the unit. Compared to the existing M30 DPC under the identical operational condition, the new prototype cooler achieved a lower PA temperature, a higher COP and higher wet-bulb and dew-point cooling effectiveness.

Further tests were undertaken to identify the optimum working air ratio, thus giving the value of 0.364 for this cooler. A series of experimental tests at this ratio indicated that the cooler consumed less fan power compared to that at the initial working air ratio of 0.44 ( $89 \mathrm{~W}$ vs. $112 \mathrm{~W}$ ), owing to the reduced discharge air rate. The increased cooling output and decreased fan power led to a significantly higher COP of the cooler compared to that at the working air ratio of 0.44 . Consequently, the cooler achieved the wet-bulb effectiveness of $112 \%-128 \%$, dew-point effectiveness of 67\%-76\% and COP of 16-52.5, which are 20\%-30\% higher than that at the initial working air ratio. Further tests on various cooling outputs indicated that the 
lower cooling power led to the slightly increased wet-bulb and dew-point effectiveness and significantly higher COP.

Under hot \& dry (Riyadh, Las Vegas and standard test condition) and warm \& dry (Kashi) climatic condition, the prototype cooler presented very high COP values ranging from 35.3 to 52.5. Under warm \& humid (Beijing) climatic condition, the cooler had a COP as low as 16.5. Under humid climatic condition, air dehumidification is a must to meet the indoor comfort requirement, the cooling performance of the proposed dew point cooler would get a great lift with the pre-dehumidification process. Therefore, in view of real application, it is recommended for humid region the proposed dew point cooler had better work with a predehumidification process to allow its full potential to be released.

It should be of particular interest that the new cooler had the significantly higher COP compared to the commercial DPC of the same sizes (52.5 vs. 18). This created an opportunity to develop a new cooler with the significantly enhanced energy efficiency, greatly reduced power use and much smaller unit size, thus extending its applications worldwide. This research will therefore contribute to realisation of the global energy saving and carbon reduction targets, and bring about the enormous economic, environmental and sustainability benefits to the world.

\section{Acknowledgements}

The authors would acknowledge our sincere appreciation to the financial supports from the University of Hull, Engineering and Physical Sciences Research Council (EPSRC), Innovate UK and Ministry of Science and Technology of China (EP/M507830/1).

\section{References}

[1] Pérez-Lombard, L., J. Ortiz, et al. A review on buildings energy consumption information, Energy and Buildings, vol. 40 (2008), pp. 394-398.

[2] Jiang, Y. Chinese building energy consumption situation and energy efficiency strategy, New Architecture (in Chinese) (2008). 
[3] K.J. Chua, S.K. Chou, W.M. Yang, J. Yan. Achieving better energy-efficient air conditioning - A review of technologies and strategies. Applied Energy 104 (2013) 87-104

[4] Barnard N. and Jaunzens D. 2001. Low Energy Cooling - Technology Selection and Early Design Guidance, Building Research Estabilishment Ltd, London.

[5] Behne M. 1997. Alternatives to Compressive Cooling in Non-Residential Buildings to Reduce Primary Energy Consumption, Final report, Lawrence Berkeley National Laboratory, Berkeley, California.

[6] Zhang, L.Z.. Energy performance of independent air dehumidification systems with energy recovery measures. Energy, 2006. 31(8-9): p. 1228-1242.

[7] Daou, K., Wang, R. Z., Xia, Z. Z.. Desiccant cooling air conditioning: a review. Renewable and Sustainable Energy Reviews, 2006. 10(2): p. 55-77.

[8] Chen, Q., Pan, Ning., Guo, Zeng-Yuan. A new approach to analysis and optimization of evaporative cooling system II: Applications. Energy, 2011. 36(5): p. 2890-2898.

[9] Goshayshi, H.R., Missenden, J. F., Tozer, R. Cooling tower - an energy conservation resource. Applied Thermal Engineering, 1999. 19(11): p. 1223-1235.

[10] Velasco Gómez E, Tejero González A, Rey Martínez FJ. Experimental characterisation of an indirect evaporative cooling prototype in two operating modes. Applied Energy 2012;97:340-6.

[11] Campaniço H, Hollmuller P, Soares PMM. Assessing energy savings in cooling demand of buildings using passive cooling systems based on ventilation. Applied Energy 2014;134:426-38.

[12] Maheshwari GP, Al-Ragom F, Suri RK. Energy-saving potential of an indirect evaporative cooler. Applied Energy 2001;69:69-76

[13] Z Duan, et al. Indirect evaporative cooling: Past, present and future potentials, Renewable and Sustainable Energy Reviews 16 (2012) 6823-6850.

[14] Stoitchkov, N.J., Dimitrov, G. I.. Effectiveness of crossflow plate heat exchanger for indirect evaporative cooling: Efficacité des échangeurs thermiques à plaques, à courants 
croises pour refroidissement indirect évaporatif. International Journal of Refrigeration, 1998. 21(6): p. 463-471.

[15] Elberling L. Laboratory Evaluation of the Coolerado Cooler-Indirect Evaporative Cooling Unit. Pacific Gas and Electric Company; 2006.

[16] Zhao X., Li J. M., Riffat S. B. Numerical study of a novel counter-flow heat and mass exchanger for dew point evaporative cooling. Applied Thermal Engineering 2008; 28: 1942 51.

[17] Zhan C. et al. Comparative study of the performance of the M-cycle counter-flow and cross-flow heat exchangers for indirect evaporative cooling - paving the path toward sustainable cooling of buildings. Energy 36(2011) $6790-6805$.

[18] F. Bruno. On-site experimental testing of a novel dew point evaporative cooler. Energy and Buildings 43 (2011) 3475-3483.

[19] B. Riangvilaikul, S. Kumar. An experimental study of a novel dew point evaporative cooling system. Energy and Buildings 42 (2010) 637-644.

[20] Hasan A. Going below the wet-bulb temperature by indirect evaporative cooling: analysis using a modified?-NTU method. Applied Energy 2012;89:237-45.

[21] J. Lin, K. Thu, T. Bui, R. Wang, K. C. Ng, K.J. Chua. Study on dew point evaporative cooling system with counter-flow configuration. Energy Conversion and Management 109 (2016)153-165.

[22] X. Cui, K.J. Chua, W.M. Yang. Numerical simulation of a novel energy-efficient dewpoint evaporative air cooler. Applied Energy 2014; 136:979-88.

[23] X. Cui, K.J. Chua, W.M. Yang, K.C. Ng, K. Thu, V.T. Nguyen. Studying the performance of an improved dew-point evaporative design for cooling application. Applied Thermal Engineering 63 (2014) 624-633.

[24] J. Lin, K. Thu, T.D. Bui, R.Z. Wang, K.C. Ng, M. Kumja, K.J. Chua. Unsteady-state analysis of a counter-flow dew point evaporative cooling system. Energy 113 (2016) 172-185. 
[25] D. Pandelidis, S. Anisimov. Numerical analysis of the heat and mass transfer processes in selected M-Cycle heat exchangers for the dew point evaporative cooling. Energy Conversion and Management 90 (2015) 62-83.

[26] D. Pandelidis, S. Anisimov. Numerical study and optimization of the cross-flow Maisotsenko cycle indirect evaporative air cooler. International Journal of Heat and Mass Transfer 103 (2016) 1029-1041.

[27] A. Sohani, H. Sayyaadi, S. Hoseinpoori. Modeling and multi-objective optimization of an M-cycle cross-flow indirect evaporative cooler using the GMDH type neural network. International journal of refrigeration 69 (2016) 186-204.

[28] S. Moshari, G. Heidarinejad. Numerical study of regenerative evaporative coolers for sub-wet bulb cooling with cross- and counter-flow configuration. Applied Thermal Engineering 89 (2015) 669-683.

[29] Chen Y, Yang H, Luo Y. Parameter sensitivity analysis and configuration optimization of Indirect Evaporative Cooler (IEC) considering condensation. Applied Energy 2016; 104:87-104.

[30] A.E. Kabeel, M. Abdelgaied. Numerical and experimental investigation of a novel configuration of indirect evaporative cooler with internal baffles. Energy Conversion and Management 126 (2016) 526-536.

[31] B. Riangvilaikul, S. Kumar. Numerical study of a novel dew point evaporative cooling system. Energy and Buildings 2010; 42: 2241-50.

[32] B. Riangvilaikul, S. Kumar. An experimental study of a novel dew point evaporative cooling system. Energy and Buildings 42 (2010) 637-44.

[33] M. Jradi, S. Riffat. Experimental and numerical investigation of a dew-point cooling system for thermal comfort in buildings. Applied Energy 132 (2014) 524-535.

[34] P. Xu, X. Ma, D. Thierno M. O., X. Zhao, K. Fancey. Numerical investigation of the energy performance of a guideless irregular heat and mass exchanger with corrugated heat transfer surface for dew point cooling. Energy 109 (2016)803-817. 
[35] P. Xu, X. Ma, X. Zhao, K. S. Fancey. Experimental investigation on performance of fabrics for indirect evaporative cooling applications. Building and Environment, 110 (2016) 104-114.

[36] H. Bai, X. Ding, P. Xu, J. Li, X. Zjap. Even liquid distribution of intensive formula. CN205718642U. http://www.psssystem.gov.cn/sipopublicsearch/patentsearch/showViewList-jumpToView.shtml

[37] Heating, ventilating, air conditioning and refrigeration - CIBSE Guide B. London: Chartered Institution of Building Services Engineers, 2005

[38] ISO 5801. Industrial Fans_-Performance Testing Using Standardized Airways; 2007.

[39] ASHRAE. ASHRAE handbook Fundamentals Volume: SI edition, American Society of Heating, Refrigerating and Air-Conditioning Engineers, 2009, Chapter 4, pp 4.18.

[40] ASHRAE. ANSI/ASHRAE standard 143-2000, Method of test for rating indirect evaporative coolers. American Society of Heating, Refrigerating and Air-Conditioning Engineers, Inc. GA 30329, 2000.

[41] J. P. Holman. Experimental Methods for Engineers, Eighth Edition. McGraw-Hill Education, New York, 2012. pp. 60-96.

[42] Environmental design - CIBSE Guide A. The Yale Press Ltd, page 2-28 to 2-23.

[43] H. Xuan, B. Ford. The application of passive downdraught evaporative cooling in hot and dry climate of China. Proceedings of 27th Conference on Passive and Low Energy Architecture, Louvain-La-Neuve, Belgium, 13-15, July 2011, pp745.

[44] Australian Standard AS 2913-2000. Evaporative Air Conditioning Equipment. 2000.

[45] https://www.britannica.com/science/Koppen-climate-classification 